\title{
An Intraday Pricing Model of Foreign Exchange Markets
}

\begin{abstract}
Market makers learn about asset values as they set intraday prices and absorb portfolio flows. Absorbing these flows causes inventory imbalances. Previous work has argued that market makers change prices to manage incoming flows and offset inventory imbalances. This study argues that they have multiple instruments, or ways to manage inventory imbalances and learn about evolving asset values. Hence, they smooth inventory levels and update prior information about assets using multiple instruments. In ignoring other instruments, previous studies have ignored the information that these provide and overemphasize the role of price changes in inventory management. The model presented here provides new estimates of asymmetric information and inventory effects, the price impact of each instrument, the cost of liquidity, and the impact of an intervention on these costs.
\end{abstract}




\section{INTRODUCTION}

The evidence supporting a tight relationship between a market's absorption of portfolio flows and its assets' returns is mounting. ${ }^{1}$ It implies that asset returns depend on how traders interact with each other and with end users. The question now is how long market trading affects asset returns. Assuming that asset fundamentals follow a random walk, there could be permanent effects if trading reveals new information. For example, traders aggregating portfolio flows may also aggregate information dispersed in the economy. Conversely, the market's temporary indigestion from absorbing large portfolio shifts may imply transitory effects, as in microstructure inventory models. At the level of the individual trader, however, there is surprisingly little (if any) evidence supporting theoretically predicted inventory effects. This paper presents a new model of asset trading that shows evidence of both information and inventory effects at the individual trader level. The empirical results link portfolio flows to asset prices at the most micro level, and provide direct estimates of the cost of liquidity, asymmetric information, and inventory effects. The model suggests that previous studies have underestimated, if not missed or even rejected these effects. An example illustrates why.

Consider a foreign exchange (FX) dealer who is trading U.S. dollar-euro and watching the price of the currency fluctuate throughout the day. Assume that the dealer is constrained with a finite inventory (or, equivalently, inventory costs). If random-walk asset values drive incoming trades, she must respond with an inventory-management strategy or exhaust her supply. Past models suggest that this dealer divert her price away from the equilibrium full-information value to induce trades that compensate for inventory imbalances. But changing prices to induce trades equates to intentionally selling low or buying high. What if there is another way? Specifically, in FX, she can call other dealers and unload her inventory imbalances on them. This allows the dealer another instrument for managing inventory and learning about asset values. In this example, the dealer's instruments are to change prices to induce incoming trades (i.e., incoming order flow), or to call others and use outgoing trades (i.e., outgoing order flow).

If multiple increasing-marginal-cost instruments are available for managing inventory, the dealer optimally spreads her inventory management across all of them. Furthermore, just as incoming order flow provides information about asset values, so do other instruments used for managing inventory, such as calling out to other dealers. The dealer may use this information to update her prior beliefs about asset values and adjust inventory levels. Hence, part of observed inventory and price changes may be correlated with innovations in information but be unrelated to either inventory carrying costs or incoming order flow. This paper models this phenomenon in the context of foreign exchange markets. In the model, the ability to make outgoing trades alters both how dealers control inventory

\footnotetext{
${ }^{1}$ Examples in equity markets include Froot, O'Connell and Seasholes (2001), and Froot and Ramadorai (2001a). Examples in foreign exchange markets include Evans and Lyons (2002), Froot and Ramadorai (2001b), and Rime (2001).
} 
through price setting and how they learn about asset values. Ignoring outgoing orders leads to both neglecting the role of information learned from these orders and overemphasizing price changes in inventory management. This implies that previous microstructure models misspecify and bias estimates of information and inventory effects.

Microstructure models study trading costs and payoffs reflected in asset returns that dividend discounting ignores. They point to two general microstructure-pricing effects. The first is the inventory effect, in which the specialist must manage a finite stock of the asset against a demand that responds to a random-walk fundamental value. ${ }^{2}$ In this situation, if the specialist passively fills orders, the probability of a stock out is unity. Hence, inventory models argue that the specialist changes her price away from the expected asset value to induce trades that unwind undesired positions. The second effect is the asymmetric information effect, ${ }^{3}$ where the specialist faces a market where some agents have more information about the asset's equilibrium value. Here she will recognize that the incoming order flow reflects this information and will change her price accordingly.

Empirical studies have found evidence of asymmetric information in equity markets; ${ }^{4}$ however tests for inventory effects are unsuccessful. For example, Madhavan and Smidt (1991) and Hasbrouck and Sofianos (1993) do not find inventory effects. Madhavan and Smidt (1993) only find evidence of unexpectedly long-lived effects by modeling inventory mean reversion with shifts in the desired inventory level. Manaster and Mann (1996) actually find robust effects opposite to theoretical predictions. Lyons (1995) extends microstructure models to foreign exchange markets and does find inventory effects; however, Romeu (2001) revisits the Lyons (1995) data and finds evidence of model misspecification, and specifically that inventory and information effects are not simultaneously present in subsamples. Other studies of foreign exchange markets also fail to find inventory effects. ${ }^{5}$ Clearly, the evidence supporting inventory effects is at best a mixed bag.

To investigate inventory effects, the model in this study uses the over-the-counter institutional structure of FX markets. At its heart is the idea that dealers exploit every alternative when rebalancing portfolios, rather than relying on only price-induced order flow to change their portfolio composition. As dealers face increasing marginal losses for inducing flows, they turn to other methods of unloading unwanted positions. The decentralized nature

\footnotetext{
${ }^{2}$ For example, Stoll (1978), Amihud and Mendelson (1980), Ho and Stoll (1981, 1983), O’Hara and Oldfield (1986) among others.

${ }^{3}$ For example, Kyle (1985), Glosten and Milgrom (1985), Admati and Pfleiderer (1988), Easley and O'Hara (1987, 1992), among others.

${ }^{4}$ For example, Hasbrouck (1991 a, b), Hasbrouck (1988), Madhavan and Smidt (1991, 1993), among others.

${ }^{5}$ Yao (1998) and Bjonnes and Rime (2000) find no evidence of inventory effects. The former suggests that it is due to dealers' aversion to revealing their position (or private information) through inventory-induced bid shading, whereas the latter suggest that the introduction of electronic brokering is the cause. The model here suggests that misspecification is the cause.
} 
of the foreign exchange market offers a clear opportunity to observe this phenomenon. The conclusions suggest that previous models are misspecified because they neglect alternatives to controlling inventory through price-induced flows. The model presented here shows why previous models are misspecified and fail empirically.

Previous studies address the decentralized nature of FX markets both at the dealer level, and at the general equilibrium level. At the dealer level, the approach is to extend Madhavan and Smidt (1991) - for example, see Lyons (1995). The model presented here suggests that the basic dealer-pricing behavior postulated in those studies is not optimal. Mello (1995) also conjectures that a dealer may have multiple instruments and non-linear pricing behavior, as presented here. At the general-equilibrium level, models such as Lyons (1997) favor modeling dealer pricing with multiple instruments. That study argues that high FX volume might be due to dealers passing on inventory imbalances.

Finally, the principle behind this paper is not limited to foreign exchange trading. All market makers have an incentive to minimize guaranteed losses from inducing trades via price changes. That alternatives exist in FX is clear; however, in other markets alternatives exist as well. For example, Madhavan and Sofianos (1997) find that New York Stock Exchange (NYSE) specialists engage in selectively trading to balance inventory. Previous equity market studies possibly overemphasize the role of prices in inventory management and miss other inventory effects. In addition, if previous models account perfectly for inventory costs, they still overlook price changes resulting from new information that alternative instruments yield. Accounting for both these effects presents more complex behavior, where the market maker is using multiple instruments to both manage inventory and update priors.

Empirical tests support the model and offer several novel results. For example, asymmetric information effects driving price changes are twice as large as previously estimated; one can graphically compare prices with the new information signals that the dealer sees. Inventory pressure is less present in price changes than was previously estimated. After controlling for inventory and information effects, the base bid-ask spread is wider than previously estimated. When setting prices, the dealer plans to trade out less than one-quarter of the difference between her current and the optimal inventory positions. The cost of inducing a standard ( $\$ 10$ million) incoming trade is about 1.5 pips (a pip is the smallest price increment in a currency ${ }^{6}$ ) or $\$ 1,000$. The cost of executing an outgoing trade of the same size is 9 to 10 times higher. The dealer's observed incoming trades are, however, 9 to 10 times greater than outgoing trades, both in number and in daily volume. Hence, outgoing orders trade at a premium, which is consistent with other studies of dealer behavior.

A Fed intervention increases the aymmetric information impact of incoming trades on price changes but decreases that of outgoing trades. An intervention lowers the cost by 50 percent of inducing an incoming trade and by 5 percent of executing an outgoing trade. It also lowers inventory costs and tightens the spread. The intervention temporarily moves

\footnotetext{
${ }^{6}$ The value depends on the currency pair. The data used here are dollar/deutsche mark, so a pip is DM 0.0001 .
} 
prices about 6.7 pips per $\$ 100$ million (Fed purchases of $\$ 300$ million move prices about 20 pips), which supports other studies. ${ }^{7}$ By comparison, a 20-pip move in our dealer's price induces a purchase of $\$ 122$ million.

Finally, the model addresses the broader relation between portfolio flows and asset prices. It suggests that with multiple instruments, market participants share intraday inventory more efficiently. That is, dealers exhaust the gains from sharing a large inventory position more quickly and with less price impact in this model. As a result, the transitory effects of inventory imbalances are present, albeit less important in determining intraday price changes than estimated previously. Furthermore, multiple instruments facilitate a more efficient aggregation of the dispersed information embedded in order flow. This information translates into permanent price movements. Hence, while both transitory and permanent effects are present in the data, the evidence favors a permanent impact of portfolio flows on prices.

The paper is organized as follows. Section II describes the theoretical framework and the model solution, which is detailed in the Appendix I. Section III shows empirical estimates, tests of the model, and discusses intervention effects. Section IV concludes. Estimation details are in Appendix II.

\section{An Intraday Foreign ExChange Pricing Model}

This section extends the Madhavan and Smidt (1993) framework in which an uninformed market maker with inventory carrying costs sets prices in a market with informed agents. Optimally, the market maker extracts information from arriving order flow, and sets prices to induce inventory-balancing trades. A real FX dealer only sets prices when she passively receives an order (i.e., another dealer initiates the trade). ${ }^{8}$ These prices are the focus of this study. Besides setting prices, however, she can initiate interdealer bilateral, brokered, or IMM Futures trades, as well as receive information from these, the financial press, news and advisory services, the sales and floor managers, and other sources. At no time does she set interdealer prices under any of these alternatives; however, they may indirectly affect her price setting. It is intractable to model all these alternatives explicitly, and the data available (inventory levels, incoming orders, and their corresponding prices) would limit empirical tests of any such model. These limitations withstanding, the dealer modeled here has two instruments for balancing inventory: inducing order flow through price changes, and initiating outgoing trades with others at their prices. She also has two instruments for updating priors: information reflected in incoming quantities, and information reflected in unplanned (at the time of price-setting) outgoing quantities.

\footnotetext{
${ }^{7}$ Evans \& Lyons (1999) estimate 5 pips and Dominguez and Frankel (1993) estimate 8 pips per $\$ 100$ million.

${ }^{8}$ An extensive description of the Foreign Exchange (FX) market's institutional make-up can be found in Lyons (2001). FX is traded bilaterally, over-the-counter, and privately, via computer emailing systems called Reuters Dealing. There are also electronic brokers similar to bulletin boards, provided by Reuters or EBS. Most large trades are done via the Reuters Dealing system.
} 
The following sections formalize this modeling approach. Subsection A. describes the model setting: the market, inventory, capital, and information variables. Subsection B. shows the optimal updating using multiple informative signals. Subsection C. shows the optimal inventory management, and the model solution. Subsection D. shows the model nesting previous work, and their misspecifications. Proofs are in the appendix.

\section{A. The Market}

Consider an economy where a dealer holds a portfolio of three assets. She only makes markets in the first, a risky asset with a full information value denoted by $v_{t}$, which evolves as a random walk. Write this value as:

$$
v_{t}=v_{t-1}+\theta_{t}, \quad \theta \sim N\left(0, \sigma_{v}^{2}\right) .
$$

The second is an exogenously endowed risky asset that is correlated with the first, and generates income $y_{t}$. The third is capital, the risk-free zero-return numeraire, denoted by $K_{t}$. The distribution of the two risky assets is: ${ }^{9}$

$$
\left(\begin{array}{l}
v_{t} \\
y_{t}
\end{array}\right) \equiv N\left(\left(\begin{array}{c}
v_{t-1} \\
0
\end{array}\right),\left[\begin{array}{cc}
\sigma_{v}^{2} & \sigma_{v y} \\
\sigma_{v y} & \sigma_{y}^{2}
\end{array}\right]\right) .
$$

The dealer's total wealth is:

$$
W_{t}=v_{t} I_{t}+K_{t}+y_{t}
$$

With $I_{t}$ being the dealer's inventory or risky asset position.

The market is open for $t=1,2, \ldots, T$ periods. The terminal date $T$ is unknown, however, at the beginning every period $t=T$ with probability $(1-\rho)$. Hence, every period the probability that the market closes is $(1-\rho)$, at which time the dealer liquidates her position and pays a inventory carrying cost. ${ }^{10}$ With probability $\rho, t \neq T$, so the dealer engages in trading activities, pays the inventory carrying cost, and goes on to the next period.

Figure 1 (page 19) depicts the timing of the model. The total change in the dealer's inventory from one event to the next occurs in two stages. In the first stage, the dealer faces an incoming order (denoted by $q_{j t}$ ) and knows her inventory (denoted by $I_{t}$ ). Part of $q_{j t}$ comes from informed traders who know the full information value $\left(v_{t}\right)$. The informed part of $q_{j t}$, denoted by $Q_{t}$, is driven by differences between the dealer's price, denoted $p_{t}$, and the asset value $v_{t}$ :

$$
Q_{t}=\delta\left(v_{t}-p_{t}\right), \quad \delta>0 .
$$

The rest of the incoming order is an uninformed or liquidity component, denoted by $X_{t}$ :

$$
X_{t} \equiv N\left(0, \sigma_{X}^{2}\right) \text {. }
$$

\footnotetext{
${ }^{9}$ Note that this is a one-period-ahead conditional distribution, as the unconditional distribution would have a time-varying variance.

${ }^{10}$ The inventory carrying cost, shown below, follows Madhavan and Smidt (1993). It is a cost proportional to the variance of the dealer's wealth.
} 
One can think of the uninformed as quantities demanded by parties not monitoring the markets or constrained to trade independent of price, for reasons not modeled here. The dealer only observes the aggregate order, $\left(q_{j t}\right)$, and sets the price. Hence, the incoming order flow is:

$$
q_{j t}=Q_{t}+X_{t}=\delta\left(v_{t}-p_{t}\right)+X_{t}
$$

At the time of setting prices, the dealer knows that later she can call others and trade an outgoing quantity (denoted $q_{t}^{\text {out }}$ ). This is depicted in upper box of Figure $1 . q_{t}^{\text {out }}$ indicates the dealer's desired outgoing quantity in expectation, and conditional on information available at the time of price setting. Because the dealer has $q_{t}^{\text {out }}$ available, she does not control inventory solely through price induced order flow. In this sense, $q_{t}^{\text {out }}$ captures the planned amount the dealer prefers to trade out rather than hold (and pay the inventory carrying cost), or dispense via price-induced incoming trades.

While our dealer is trading $q_{t}^{\text {out }}$, however, there will be exogenous quantity shocks to her inventory, as shown in Figure 1. The source of these shocks can be unplanned trading with clients of our dealer's bank (her employer), other bank dealers, brokered trading, the trading floor manager, and so on. These shocks perturb the dealer's inventory position beyond the planned quantity, $q_{t}^{\text {out }}$. Denote these disturbances as $\gamma_{t}$. Accordingly, the total quantity $\left(q_{t-1}^{\text {out }}+\gamma_{t-1}\right)$ will be the inventory change apart from the incoming trade $\left(q_{j t-1}\right)$ from $t$ 1 to $t$. Hence, last event's inventory $\left(I_{t-1}\right)$, adjusted for the last incoming trade $\left(q_{j t-1}\right)$, as well as the total realized outgoing quantity $\left(q_{t-1}^{\text {out }}+\gamma_{t-1}\right)$, yields next event's inventory $\left(I_{t}\right)$.

An example illustrates the trading process. Suppose our dealer begins the day with inventory at zero. The interdealer computer communicates that a dealer wants to sell her 1 unit. Here, $t=1, I_{l}=0, q_{j l}=-1$. Suppose our dealer optimally sets the price to $5\left(p_{I}=5\right)$, and plans to buy 2 units from other dealers when trade 1 is through $\left(q_{1}^{\text {out }}=2\right)$. In the data we do not see our dealer's trading until someone initiates another trade with her over the interdealer computer. At the next incoming trade $(t=2)$, suppose that $I_{2}=6$, and $q_{j 2}=-1$. Considering the last trade's inventory, incoming and planned outgoing quantities, $I_{2}$ should be three. It is six, which implies that $\gamma_{1}$ was 3 . That is, the dealer planned to aggressively buy 2 after she passively buys 1 from the incoming trade. Her inventory should be three, but it is six, which implies that the unplanned inventory shock was 3.

Assume further that new information and events occurring in the clock time between events $t-1$ and $t$ are driving the quantity shocks $\left(\gamma_{t-1}\right)$; hence, assume a linear function (denoted $\kappa())$ such that: ${ }^{11}$

\footnotetext{
${ }^{11}$ The general form of (7) is chosen for ease of exposition; the conclusions are robust to different functional forms.
} 


$$
\kappa\left(\gamma_{t-1}\right) \equiv \alpha_{0}+\alpha_{1} \gamma_{t-1}=\theta_{t}+\varepsilon_{t}, \quad \varepsilon_{t} \sim N\left(0, \sigma_{\varepsilon}^{2}\right)
$$

In equation (7), the unexpected inventory shock (noisily) signals innovations in the asset value that occur while the dealer executes outgoing trades. $\gamma_{t-1}$ is informative because after the dealer chooses her outgoing quantity $\left(q_{t-1}^{\text {out }}\right)$, she should trade this quantity and nothing else; that is, the choice made at $t-1$ is optimal until new information (at the next incoming order, $q_{j t}$ ) arrives. The only reason our dealer would deviate from the optimal outgoing quantity ( $\left.q_{t-1}^{\text {out }}\right)$ between $t-1$ and $t$ is that new information is revealed. Hence, the evolution of $v_{t}$ can be inferred from $\gamma_{t-1}$. If this is the case, then the total outgoing quantity will reflect the desired quantity ( $q_{t-1}^{\text {out }}$ ) plus the quantity driven by new information $\left(\gamma_{t-1}\right)$. $\gamma_{t-1}$ captures that information in the dealer's decision process beyond strictly what is derived from incoming order flow, while keeping the analysis tractable. ${ }^{12}$

In summary, the identity that describes the evolution of inventory is:

$$
I_{t} \equiv I_{t-1}-\delta\left(v_{t-1}-p_{t-1}\right)-X_{t-1}+q_{t-1}^{\text {out }}+\gamma_{t-1}
$$

In contrast, at the time of setting prices, the dealer's expectation of next period's inventory is:

$$
E\left[I_{t+1} \mid \Omega_{t}^{j}\right]=I_{t}-q_{j t}+q_{t}^{\text {out }}
$$

Our dealer manages inventory because she pays a cost every period that is proportional to the variance of her portfolio wealth, which includes the cash value of the inventory. One can motivated this cost, for example, by risk aversion or marginally increasing borrowing costs. Assume that the dealer incurs a capital charge due to the $\gamma$ shocks. That is, any gains (losses) entering into the dealer's wealth due to $\gamma$ are subtracted (added) from (to) the dealer's capital, $K_{t}$ at a cost $v_{t \cdot}{ }^{13}$ In the previous example, the dealer would pay inventory costs on $q_{1}^{\text {out }}$, but not on $\gamma_{1}$ at the end of the trade. Incorporating this charge, at trade $t$ the dealer's wealth position is given by:

$$
W_{t}=v_{t}\left(E\left[I_{t} \mid \Phi_{t-1}\right]+\gamma_{t-1}\right)+\left(E\left[K_{t} \mid \Phi_{t-1}\right]-v_{t} \gamma_{t-1}\right)+y_{t}
$$

This assumption implies that the dealer only pays the inventory carrying cost on the expected wealth, and the inventory carrying cost due to quantity shocks is canceled by the

\footnotetext{
${ }^{12}$ Although they include multiple informative signals, incoming order flow is the only source of private information in Madhavan and Smidt (1991) or Lyons (1995).

${ }^{13}$ This assumption simply eases the exposition of the problem at hand, and keeps it in a discrete time framework. As discussed below, $\gamma$ has a time-varying variance. This complicates calculating the variance of the portfolio - this would involve moving the entire model to a continuous time framework. Because of the discrete-time arrival process of incoming calls, this would make for a cumbersome solution with very little added payoff in relation to the problem of how dealers set prices on incoming orders. It would not, however, change the model's conclusions regarding price setting with multiple instruments.
} 
capital charge. The appendix shows that the inventory cost is a function of the deviations from the optimal hedge ratio of the risky assets, given by $I^{d}$. This hedge ratio optimally smooths the dealer's wealth, and enters the inventory cost as:

$$
c_{t}=\omega\left[\sigma_{W}^{2}\right]=\omega\left[\phi_{0}+\phi_{1}\left(I_{t}-I^{d}\right)^{2}\right] \text {. }
$$

\section{B. The Information Structure}

What is of interest is how the dealer sets prices, which occurs only in the event of an incoming trade. The incoming trade is, in part, based on the equilibrium asset value, $v_{t}$. The dealer wishes to learn this value, and she will estimate the full information value of the asset based on her trading history and any publicly available information. The appendix shows the solution to the dealer's learning problem modeled as a rational expectations consistent

Kalman filter. ${ }^{14}$ This section outlines the two sources of information available for learning $v_{t}$ and updating prior beliefs in this model. Denote the dealer's expectation of the full information value of the risky asset as:

$$
E\left[v_{t} \mid \Phi_{t}\right]=\mu_{t}
$$

The dealer has two ways of updating $\mu_{t-1}$ and learning about the full information value of the asset $v_{t}$. The first is the incoming trade, $q_{j t}$. From this incoming quantity the dealer extracts a signal of the asset value, $v_{t}$. Denote this signal by $s_{t}$. The second source of information about $v_{t}$ is the information learned while executing the outgoing trade, which is reflected in a function of the inventory shock, $\kappa\left(\gamma_{t-1}\right)$. While both $\kappa\left(\gamma_{t-1}\right)$ and $s_{t}$ are used to update $\mu_{t-1}$, assumed that the variance of $\kappa\left(\gamma_{t-1}\right)$ is increasing in the real time (i.e., clock time) elapsed between incoming trades. That is, assume that $\operatorname{var}\left(s_{t}\right)=\sigma_{w}^{2}$ and $\operatorname{var}\left(\kappa\left(\gamma_{t-1}\right)\right)=\sigma_{w}^{2} \Delta \tau$, with $\Delta \tau$ being the clock time elapsed between events $t-1$ and $t$. As the appendix shows, this gives an updating as a function of:

$$
\mu_{t}-\mu_{t-1}=(\Delta \tau / 1+\Delta \tau) s_{t}+(1 / 1+\Delta \tau) \kappa\left(\gamma_{t-1}\right) .
$$

In equation (13), as elapsed inter-transaction time gets larger $(\Delta \tau \rightarrow \infty)$ the dealer places the majority of the weight on the incoming order's information, $s_{t}$. The longer the time in between trades, the less relevant is the information from that time in relation to the incoming trade's information. Intuitively, (13) says that the moment the dealer is setting $p_{t}$, $s_{t}$ has just arrived because it is based on the incoming order itself $\left(q_{j t}\right)$. The quantity shock signal $\left(\kappa\left(\gamma_{t-1}\right)\right)$ also serves to signal the new innovation, but it arrives between $t-1$ and $t$, and hence it is not assumed to have the same precision as $s_{t}$. Instead it is assumed that $\kappa\left(\gamma_{t-1}\right)$ 's

\footnotetext{
${ }^{14}$ Alternatively, one could use a Bayesian updating model, such as Lyons (1995), Madhavan and Smidt (1991), Yao (1998) and others. These use total incoming orders (rather than the unexpected component) as signals.
} 
precision decreases (i.e., variance increases) as the clock-time elapsed from event $t-1$ to $t$ increases. As more time has passed in between trades, $\kappa\left(\gamma_{t-1}\right)$ has more noise. ${ }^{15}$

Finally, the appendix shows that the estimate of the full-information asset value, $\mu_{t}$, generates an unbiased estimate of the liquidity trade, $X_{t}$. We denote this statistic as $E\left[X_{t} \mid \Omega_{t}\right]=x_{t}$.

\section{The Dealer's Optimization}

Here the problem is set up as a stochastic dynamic programming problem; $\sim$ denote random variables, and the solution is in the appendix. The dealer solves:

$$
J\left(I_{t}, x_{t}, \mu_{t}, K_{t}\right)=\max _{p_{t}, q_{t}^{u t}} E\left\{(1-\rho)\left[\tilde{v}_{t} I_{t}+K_{t}+y_{t}-c_{t}\right]+\rho J\left(\tilde{I}_{t+1}, \tilde{x}_{t+1}, \tilde{\mu}_{t+1}, \tilde{K}_{t+1}\right)\right\},
$$

subject to the following evolution constraints:

Inventory: $\quad E\left[\tilde{I}_{t+1} \mid \Phi_{t}^{i}\right]=I_{t}-\delta\left(\mu_{t}-p_{t}\right)-x_{t}+q_{t}^{\text {out }}$,

Noise Trading:

$$
E\left[\tilde{x}_{t+1} \mid \Phi_{t}^{i}\right]=0
$$

Information:

$$
E\left[\tilde{\mu}_{t+1} \mid \Phi_{t}^{i}\right]=\mu_{t},
$$

Capital: $\quad E\left[\tilde{K}_{t+1} \mid \Phi_{t}^{i}\right]=K_{t}+p_{t} \delta\left(\mu_{t}-p_{t}\right)+p_{t} x_{t}-\left(\mu_{t}+\alpha q_{t}^{\text {out }}\right) q_{t}^{\text {out }}-c_{t}$,

Equations (11), and (14) through (18) comprise the optimization problem. (15) constrains inventory evolution. (16) constrains liquidity trades to be zero in expectation. (17) constrains the asset to a random walk. (18) constrains the capital evolution, and specifies that when the dealer trades $q_{t}^{\text {out }}$, she expects to pay a price centered on the full-information value, and with a price impact $\left(\mu_{t}+\alpha q_{t}^{\text {out }}\right)$. $\alpha$ captures the price impact of a marginal increase in her outgoing quantity. Hence the dealer, while not a monopolist in the interdealer market, does face a downward sloping demand curve in her trades. Assuming that the dealer faces $\alpha$ when trading out is similar to assuming that there is marginal declining revenue from selling to an informed agent (recall that revenue from the sale is $p \delta(\mu-p)$ ). Modeling outside prices explicitly requires a general equilibrium framework that normally mutes dealer level pricing effects. $^{16}$ The appendix shows the model solution to be:

$$
p=\mu+\beta\left(\frac{\delta \alpha}{(1+\delta \alpha)}\right)\left[I-I^{d}\right]+\left(\frac{1+\delta(\beta+\delta)}{2 \delta(1+\delta \alpha)}\right) x ;
$$

\footnotetext{
${ }^{15}$ One might argue that as $\Delta \tau \rightarrow 0$, the dealer has less time to carry out planned transactions, but she can always elect to not answer the incoming calls until the part of planned transactions she wants done are satisfied. Furthermore, the increasing frequency of incoming calls and shortening of inter-transaction time would itself be a source of new information for the dealer, as suggested by Easley and O'Hara (1992).

${ }^{16}$ For example, the Evans and Lyons (2002) assumes that dealers submit bids simultaneously and transparently, which in equilibrium implies that prices be based on common information only. This paper avoids such restrictions because the focus is on interdealer price dynamics, but this comes at the expense of the general equilibrium insights.
} 


$$
\begin{gathered}
q^{\text {out }}=\left(A_{1} / A_{1}-\alpha\right)\left[-\left(I-I^{d}\right)+\delta(\mu-p)+x\right] \\
I^{\prime}=I+\beta\left(I-I^{d}\right)+\left(\frac{(1+\beta)}{2 \alpha}\right) x \\
\Delta p=\psi_{1} \eta s_{t}+A_{1}(1+\beta)\left(q_{t-1}^{\text {out }}+\gamma_{t-1}-q_{j, t-1}\right)+\psi_{2}(1-\eta) \kappa\left(\gamma_{t-1}\right)+\left(\frac{\delta A_{1}(1+\beta)+\alpha}{2 \alpha \delta}\right) \Delta x_{t}
\end{gathered}
$$

Equation (19) shows the price of the dealer as a function of the estimated asset value, $\left(\mu_{t}\right)$, the deviation from optimal inventory, $\left(I_{t}-I^{d}\right)$, and the liquidity shocks $\left(x_{t}\right)$. In (20) the outgoing quantity shows that as the price impact of outgoing trades goes to zero, i.e., $\alpha \rightarrow 0$, outgoing trades fully adjusts inventories to the optimal level (in the appendix, $A_{1}<0$ is shown). In this case, the price will depend only on the estimate of $v$ and the liquidity demand. In equation (22), $s_{t}$ is the information from incoming order flow $\left(q_{j t}\right)$ and the elapsed time is measured by $\eta=\Delta \tau / 1+\Delta \tau$. This equation shows that the increment in dealer price contains information-driven components from both the current incoming order $\left(\eta s_{t}\right)$, and the previous inventory shock $\left((1-\eta) \kappa\left(\gamma_{t-1}\right)\right)$. The $\left(q_{t-1}^{\text {out }}+\gamma-q_{j, t-1}\right)$ term captures component of the price change attributable to inventory pressure. Finally, the dealer changes her price due to the noise-trading component $\left(\Delta x_{t}\right)$.

Intuitively, the dealer would like to maintain inventory at the optimal level, but as a market maker she must accept incoming orders that constantly disturb her inventory position. As orders arrive $\left(q_{j, t}, q_{j, t-1}\right)$ she tries to restore balance to her inventory with $q_{t-1}^{\text {out }}$ and price changes. Adjusting back to the optimal level $I^{d}$ via $q_{t-1}^{\text {out }}$ implies absorbing the costs from the outgoing order's price impact $(\alpha)$. Adjusting inventories via price induced orders implies absorbing the certain loss to the informed traders, via $\delta\left(\mu_{t}-p_{t}\right)$. The coefficients in (22) reflect the balance between these competing losses. Furthermore, the price is centered on the best guess of $v_{t}$, which is derived from two information sources, $s_{t}$ and $\kappa\left(\gamma_{t-1}\right)$. The respective coefficients reflect the information extraction, which involves weighing these signals by the time elapsed between events.

\section{A Comparison with Existing Models}

This section shows how the model presented nests the previous dealer-level frameworks. Restricting the model to no outgoing trades, and consequently no inventory shocks, the solution would be (23). This is the Madhavan and Smidt (1993) pricing behavior for an equity market specialist;

$$
\Delta p_{t}=s_{t}+\zeta_{1}\left(I_{t}-I^{d}\right)+\zeta_{2} x_{t} \Leftrightarrow \gamma_{t} \equiv q_{t}^{\text {out }} \equiv 0 \quad \forall t \leq T .
$$

This model suggests, however, that these restrictions may shut down other avenues of inventory management available to specialists. That is, as NYSE specialists face increasing marginal costs to inventory management through price changes, they optimally spread these costs across different avenues available. For example, Madhavan and Sofianos (1997) find evidence supporting this. Hence, restrictions that yield (23) would lead to biased estimates of 
inventory effects since they overemphasize the role of changing prices to manage inventory. Romeu (2001), Bjonnes and Rime (2000), Yao (1998), Lyons (1995) and Madhavan and Smidt (1991) postulate that prices are set according to:

$$
p_{t}=\mu_{t}+\left(I_{t}-I^{d}\right)+D_{t} \text {. }
$$

Equation (24) yields the price change as:

$$
\Delta p_{t}=\beta_{0}+\beta_{1} q_{j t}+\beta_{2}\left(I_{t-1}-q_{j, t-1}+q_{t-1}^{\text {out }}+\gamma_{t-1}\right)+\beta_{3} I_{t-1}+\beta_{4} D_{t}+\beta_{5} D_{t-1}
$$

With the data used here, Romeu (2001) shows that estimates of (25) are misspecified. Breaks present in the data coincide with systematic differences in the length of intertransaction time $(\Delta \tau)$. The changes in inter-transaction times are exogenous and imply changes in the precision of the informative variables $\left(q_{j t}, \gamma_{t}\right)$. To see why these would cause breaks, rewrite (25) consistent with this paper's data generation process, and note the omitted term in brackets weighed by $\left(1-\eta_{t}\right)$ below:

$$
\Delta p_{t}=\varphi_{0}+\varphi_{1} q_{j t}+\varphi_{2}\left(-q_{j t-1}+q_{t-1}^{\text {out }}+\gamma_{t-1}\right)+\underset{\text { extraneous term }}{\left(\varphi_{3}-\varphi_{2}\right)} I_{t-1}+\varphi_{5} \Delta x_{t}+\left(1-\eta_{t}\right)\left[\underset{\rho_{4}}{\left.\varphi_{\text {omited term }} \kappa\left(\gamma_{t-1}\right)-\varphi_{1} q_{j t}\right]}\right.
$$

With $\left(\varphi_{3}-\varphi_{2}\right)=0$, so that the true process would place zero weight on lagged inventory. When inter-transaction times are long $\left(\Delta \tau \rightarrow \infty\right.$ and $\left.\left(\frac{\Delta \tau}{1+\Delta \tau}\right) \equiv \eta \rightarrow 1\right)$, this omitted term should be irrelevant. At such times, one should expect the incoming order flow coefficient $\left(\varphi_{1}\right)$ to be significant. At such times, $\operatorname{var}\left(\kappa\left(\gamma_{t-1}\right)\right) \rightarrow \infty$, hence $\gamma_{t-1}$ will be mostly noise, and uncorrelated to price changes. This would in turn make $\varphi_{2}$ less correlated with $\Delta p$ since there is no term picking up the information role for $\gamma_{t-1}$ other than the inventory term. In addition, since there is no role for $I_{t-1}$ in the equation, it is uncorrelated with the price change, and as $\varphi_{2} \rightarrow 0$, this would make $\left(\varphi_{3}-\varphi_{2}\right)$ tend to zero. Hence, one would not expect to see inventory effects at these times. When inter-transaction times are short $(\Delta \tau \rightarrow 0$, and $\eta \rightarrow 0$ ), one would see the coefficient on $q_{j t}$ become insignificant, whereas the coefficients on the inventory terms would be significant. 


\section{DATA AND EMPIRICAl TeSts}

This section empirically tests the model. The first subsection discusses the data; the second subsection estimates and tests the model (details are in the appendix). The third subsection shows the impact of an intervention on the estimates, and on $\delta$ (the cost of inducing order flow) and $\alpha$ (the cost of placing outgoing orders).

\section{A. Data Considerations}

The data set used to test the model consists of one week of a New York based foreign exchange dealer's prices, incoming order flow, inventory levels, and transaction clock times. ${ }^{17}$ Hence, $p_{t}, q_{j t}, I_{t}$, and $\Delta \tau$ (and $\eta$ ) come directly from the recordings of a Reuters Dealing 2000-1 computer trading system. Out of the 843 transactions, the four overnight price changes are discarded, since the model at hand deals exclusively with intraday pricing.

The fundamental question that this model seeks to resolve is how dealers set prices, and hence, of interest is the price change equation (22). Its estimation requires knowledge of the unobservable outgoing orders, $q_{t}^{\text {out }}$, and inventory shocks, $\gamma_{t-1}, \gamma_{t}$. These are unobservable because $q_{t}^{\text {out }}$ represents the dealer's commitment to make an outgoing trade at the moment of price setting only. It is at this moment that she commits irreversibly to a price who's optimality depends on being able to trade $q_{t}^{\text {out }}$; one of the messages of this model is that the price would be different if $q_{t}^{\text {out }}$ were not available. Actual outgoing quantities may be different from the planned $q_{t}^{\text {out }}$ due to unanticipated information, frictions, or differences in the trading venues utilized to execute the outgoing trade. Although they cannot be observed, the model solution provides equations which allow estimation of $q_{t}^{\text {out }}$ and $\gamma_{t-1}, \gamma_{t}$.

The model solution also suggests that price changes depend on updating priors using two sources of information: the unexpected part of the incoming order flow $\left(s_{t}\right)$, and the unexpected outgoing order flow $\left(\gamma_{t-1}\right)$. Other models typically employ incoming order flow as a source of information; however, the use of $\gamma_{t-1}$ as a source of information is new. To get a feel for this variable, Figure 2 (page 20) superimposes cumulative daily unexpected order flow on the price, and Figure 3 does the same for cumulative daily inventory shocks (i.e., cumulative daily $\gamma_{t-1}$ ).

The vertical lines represent the end of each day of the five-day sample (Monday through Friday). The correlation of two signals with price seems to vary. For example, on Monday and Wednesday, incoming order flow appears to be a more precise signal of price

\footnotetext{
${ }^{17}$ The data are for the dollar/DM market from August 3-7, 1992. See Lyons (1995) for an extensive exposition of this data set.
} 
than inventory shocks, whereas on Friday the opposite seems to be true. In the model, elapsed clock-time affects the relative precision between these signals. Table 1 (page 21) reports the daily correlations and average intertransaction clock-time. Although these are cumulative signals, Friday gives an example of short intertransaciton clock-time, and higher correlation in the (cumulative) inventory shocks than (cumulative) order flow shocks.

\section{B. Estimation}

Table 2 (page 21) lays out the three optimality conditions of the model and their estimable forms. The first is the optimal inventory evolution, which is directly estimated and yields the optimal inventory level. The second equation partitions the non-incoming inventory change into the optimal outgoing order, $q_{t}^{\text {out }}$, and the inventory shock, $\gamma_{t}$. The final equation then estimates the change in price as the sum of the three components in the model. The first reflects information effects from incoming order flow. The second reflects inventory accumulation pressure on the price. The third reflects information from the inventory shock. Two direction-of-trade dummy variables are included to capture the fixed costs such as order processing costs, and pick up the base spread for quantities close to zero. These variables equal one if the incoming order is a purchase (i.e., the caller buys), and negative one if the incoming order is a sale (i.e., the caller sells).

The elapsed time in between transactions is measured to the minute, and estimates are robust to monotonic transformations of $\eta$. The estimate of the unobservable inventory shock proved to be problematic. Its inclusion opens the door to multicollinearity and is possibly correlated with the residual. As a result, it is instrumented out using its own lags. The unexpected incoming order flow $\left(s_{t}^{*}\right)$ is calculated as the residual of a VAR. ${ }^{18}$

$$
q_{j t}=\sum_{k=1}^{2} q_{j t-k}+\varepsilon_{t} ; \quad s_{t}^{*}=\hat{\varepsilon}_{t} .
$$

The final price change regression is estimated using non-linear least squares. The results are robust to changing initial parameter values. Table 3 (page 22) shows the estimations of the model, as well as estimates of the data using the Lyons (1995) specification. $^{19}$

The estimations indicate that the model fits the data fairly well. The asymmetric information components $\left(\mathrm{c}_{1}\right.$ and $\left.\mathrm{c}_{3}\right)$ are significant and much larger than previous estimates given by $\beta_{1}\left(10^{5}\right.$ multiply all coefficients $)$. The estimates indicate that the dealer widens her spread by between roughly 3.5 and 9 pips per $\$ 10$ million of unexpected incoming order flow or inventory shocks (double $c_{1}$ and $c_{3}$ ). This indicates a more intense asymmetric information

\footnotetext{
18 As in Hasbrouck (1991) and Madhavan and Smidt (1993). See appendix for estimation details on the generated regressors and instrumentation of the inventory shocks.

${ }^{19}$ However, Romeu (2001) finds evidence of model misspecification present in the estimates from Lyons (1995) that used here as a basis for comparison.
} 
effect; not only are they higher than previous models suggest, but there are two sources of information pushing price changes. ${ }^{20}$ In comparing information from incoming trades versus inventory shocks, price is more sensitive to the latter. This may result from outgoing trades providing a more heterogeneous and richer information component due to the variety of sources (end users, IMM Futures, etc.). Another reason may be that in practice incoming trades are larger or more frequent, so that the same unit increase will push prices less than a unit increase in inventory shocks. It may also result from this dealer's focus on providing liquidity for incoming trades, rather than aggressively trading out. ${ }^{21}$

In addition, the coefficient on inventory management $b_{2}$ is significant and tends to be similar in size to the previous models' $\beta_{2}$; however, since previous models have two inventory terms, the total inventory effect is:

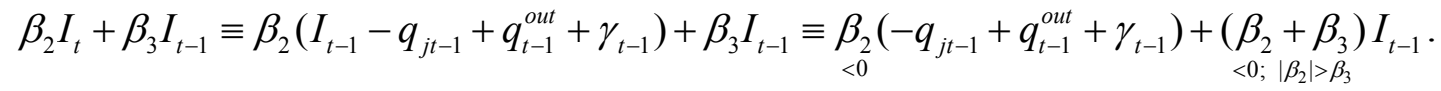

Hence, the inventory impact on price of $\beta_{2}$ is augmented by $\left(\beta_{2}+\beta_{3}\right) I_{t-1}$. Our dealer alters her price less in response to inventory accumulation than the total inventory driven change in previous models.

These differences in the estimates are due to the market maker's use of multiple increasing-marginal-cost instruments to manage inventory and learn new information. Consider the inventory overweighting of previous models. Estimations that ignore multiple instruments will overweigh the inventory component because price changes have such an important role in inventory management. The model presented here suggests that price is but one of multiple instruments used to control inventory costs. As a result, inventory accumulation is not as important in explaining price changes. Consider now why previous work underestimates the information component. Even if pure inventory pressures were perfectly explained by previous models, there is a component of inventory change driven by new information. Inventory theory cannot explain this information-driven inventory component. This component is one of multiple signals that, according to the model, vary in precision depending on elapsed clock-time. This suggests that incoming order flow can be relatively less informative at different times, and should be weighed accordingly. Previous estimations assign all information-driven price changes to the (at times, noisy) incoming order flow, and mute its true informative impact.

Finally, $c_{4}$ measures the effective spread for $q_{j t}$ close to zero. It suggests that after having controlled for information and inventory effects, the baseline spread is roughly 2.52.8 pips (twice $c_{4}$ times $10^{-5}$ ). Note that these estimates are remarkably close to the median interdealer spread observed in the FX market of 3 pips.

\footnotetext{
${ }^{20}$ A caveat here is that the model measures unexpected incoming order flow as an information signal, which is not directly comparable to previous estimates that use the entire order. In addition, the estimates are subject to measurement errors, however, the lower bound estimate is higher than the Lyons (1995) estimate.

${ }^{21}$ Lyons (1996) describes this dealer as a "liquidity machine.” As noted in section III. C. below, outgoing orders are observed about one-ninth as often as incoming orders are received.
} 
The left panel of Table 4 (page 22) shows the estimate for the optimal outgoing quantity, $q_{t}^{\text {out }}$. The estimate suggests that at every event the dealer plans to trade out less than one fourth of the difference between the current and optimal inventory, $\left(I_{t}-I^{d}\right)$. The right panel shows estimates of the inventory evolution, and the optimal inventory level, $I^{d}$, which is about two million dollars long.

The results withstand various robustness tests. First, no evidence of the presence or location of (possibly multiple) structural breaks is found. ${ }^{22}$ These tests are robust to possible heterogeneity and autocorrelation in the residuals. In addition, the estimated linear regressions use Huber/White robust standard errors. Estimation with various monotonic transformations of $\eta$ produces no significant change in the results. The adjusted $\mathrm{R}^{2}$ indicates a good fit for the data. Finally, the appendix details the estimation of several linear approximations to the non-linear equation and various tests performed as further evidence of robustness.

\section{Fed Intervention and the Cost of Liquidity}

The last five percent of recorded trades occurred while the Fed intervened to support the dollar. In Figure 2 (page 20), the sharp appreciation on the last day reflects the market reaction to the intervention. It perhaps succeeded in slowing the slide of the dollar, but was unsuccessful in sustaining a reversal. The market closed down on the day, and down from its high after the start of intervention. It involved multiple dollar purchases totaling \$300 million after the close of European markets. The exact start time is unknown; however, from the financial press three suspected times are shown in the first column of Table 7 (page 24). ${ }^{23}$ There are too few observations to meaningfully estimate the intervention in isolation. Instead, this section compares estimates of the model and the liquidity costs with and without the intervention period (i.e., 95 percent of the sample, versus 100 percent). Non-linear Wald tests fail to reject equality between the two sets of estimates, which is foreseeable given nearly identical underlying samples.

Table 3 (page 21) shows the impact of the intervention on the estimated parameters. The intervention increases the asymmetric information effect of incoming order flow $\left(c_{1}\right)$ by over 50 percent. Surprisingly, the estimate for inventory shocks $\left(c_{3}\right)$ declines, although by just 5 percent. This asymmetry may be idiosyncratic to this dealer; she is a major liquidity provider in the market, and consummates many more incoming trades. Turning to inventory effects $\left(c_{2}\right)$, these become less negative as the Fed dollar buys dollars and injects liquidity.

\footnotetext{
${ }^{22} \operatorname{Sup}\{\mathrm{F}\}$ tests based on Andrews (1993)/Bai Perron (1998).

${ }^{23}$ Quoting the Wall Street Journal, August 10, 1992: “The Federal Reserve Bank of New York moved to support the U.S. currency... as the dollar traded at 1.4720." This is the most precise documentation available of the intervention start, and that price corresponds to $12: 32 \mathrm{pm}$. Other times are selected because of reports of a mid-day start (hence, 12:02 pm), and at 12:26 pm the price jumps 36 pips, suggesting a possible intervention start at that point.
} 
This is also consistent with the tightening of the spread $\left(c_{4}\right)$. From Table 4 , the desired inventory, $I^{d}$, declines by 14 percent, indicating perhaps that the dealer (presciently) bets against an appreciation due to the intervention. Finally, the dealer increases the planned outgoing trade by 1 percent at every event.

The model estimates allow one to recover the respective costs of liquidity for trading out or inducing incoming trades (show in the appendix). That is, estimates of $\delta$ (from $\delta(\mu-p))$ and $\alpha$ (from $\left.q^{\text {out }}\left(\mu+\alpha q^{\text {out }}\right)\right)$ are recovered from the estimated parameters in Table 5 (page 23). The cost of inducing a $\$ 10$ million order (based on $\delta$ ) is presented and converted to pips, dollars, and as a percent of $\$ 10$ million. It costs our dealer 1.63 pips (about $\$ 1,100$ or just over one basis point of the order size) before the intervention, and 1.36 pips (about $\$ 900$ or less than one basis point) with the intervention. The cost of a $\$ 1$ million outgoing trade $(\alpha)$ is significantly higher. It costs 1.48 pips without the intervention and 1.42 pips including it. So, without the intervention, it is about nine times more expensive to trade \$1 million out than to induce \$1 million. During the intervention, it is over ten times more expensive! This cost disparity is stunning, but Table 6 lends support to this result and insight as to why.

Table 6 (page 21) shows the observed number of outgoing and incoming trades by the dealer. Incoming trades outnumber outgoing trades 8.5 to 1 . The table also gives the average and median sizes of incoming trades $\left(q_{j t}\right)$ and outgoing trades $\left(q_{t}^{\text {out }}\right)$. Incoming trades are slightly larger than outgoing trades, both in mean and median. These, and the fact that incoming trades are far more in number, imply incoming trades handle about nine to ten times the daily volume of dollars that outgoing trades do. This accords well with the estimated costs of the respective instruments. It suggests that the dealer primarily handles incoming trades, but occasionally uses outgoing trades, perhaps because of a need to trade with end users, some other segment of the market, or some special convenience outgoing trades provide.

Table 7 (page 24) compares the price impact of the Fed's $\$ 300$ million intervention with the price impact faced by our dealer. From the start of the intervention (12:32 pm) to the highest price, the dollar appreciated 20 pips, but it then closed 9 pips below the start. Columns (2) and (3) show that this implies -3 and 6.67 pips per $\$ 100$ million of intervention from the start to the closing and high price, respectively. Columns (4) and (5) show that if our dealer moves her price -9 (3 times -3 ) or 20 (3 times 6.67$)$ pips, she could sell $\$ 55$ million or buy $\$ 122$ million, respectively. For a given price impact, the Fed's purchases more dollars than the dealer does, since these purchases are realized against a falling market. ${ }^{24}$ These estimates are similar to those in previous work.

\footnotetext{
${ }^{24}$ Estimates are presented for other suspected intervention start times. Because these times imply a much larger price movement, they also imply a much more effective intervention. This, however, is not consistent with previous estimates of intervention price impact (pips per $\$ 100$ million), the financial press reports of the intervention's ineffectiveness, or the fact that in subsequent days, further interventions were executed in support of the dollar. These withstanding, they are presented for comparison purposes.
} 


\section{Conclusions}

The model presented incorporates the realistic options available to market makers for absorbing portfolio flows. Past models say that making markets entails moving prices away from the full information value to induce trades that compensate inventory imbalances. But this equates to intentionally selling low or buying high to avoid paying inventory costs. This paper suggests that there is a better way.

One clear example is that in FX, the dealer has the ability to call others in the market and unload her unwanted inventory on them. Of course this is not to suggest that outgoing orders are a panacea for inventory problems, so these are modeled with price impact (i.e., increasing marginal costs). However, at the margin, she will equate the loss of trading unwanted inventory to incoming calls with the marginal price impact (i.e., the loss of trading unwanted inventory in outgoing calls) and with the marginal loss of the inventory imbalance (i.e., the marginal inventory carrying cost).

In addition, these outgoing calls do not occur in a vacuum. As long as events transpire during the outgoing call period, the dealer will learn through trading at those times and update her beliefs. These updates bring about price changes that neither inventory costs nor incoming order flow can explain. And FX dealers are just one example of market makers who smooth costs over multiple instruments. This paper argues that one should consider where dealers or specialists might be substituting away from conventional inventory costs when modeling price setting. Price-induced order flow is one of a multiplicity of informative instruments available to market makers.

The estimations support the proposed model and provide several novel empirical results. Generally, these indicate that previous studies overemphasize the role of price changes in inventory management, since no other instruments are considered. This omission biases downward the role of information in price changes, can make inventory effects appear insignificant, and tightens the bid-ask spread. At the time of price setting, planned outgoing trades are less than one-quarter of the difference between current and optimal inventory positions. The cost of inducing a $\$ 10$ million trade is about 1.5 pips, or $\$ 1,000$. Outgoing trades are observed roughly one-tenth less frequently than incoming trades, and are estimated to be ten times more expensive. A Fed intervention increases the informativeness of order flow, and lowers the cost of liquidity for the dealer. It also lowers inventory costs and tightens the spread.

Finally, the model addresses the broader relation between portfolio flows and asset prices. The presence of inventory effects suggests that part of observed price changes is transitory. However, with multiple instruments, dealers exhaust the gains from sharing a large inventory position with less price impact. As a result, the transitory component of price changes is less important than the information components from the multiple instruments. Hence, while both transitory and permanent effects are present in the data, the model favors a permanent impact of portfolio flows on prices. 
Figure 1. The Timing of the Model

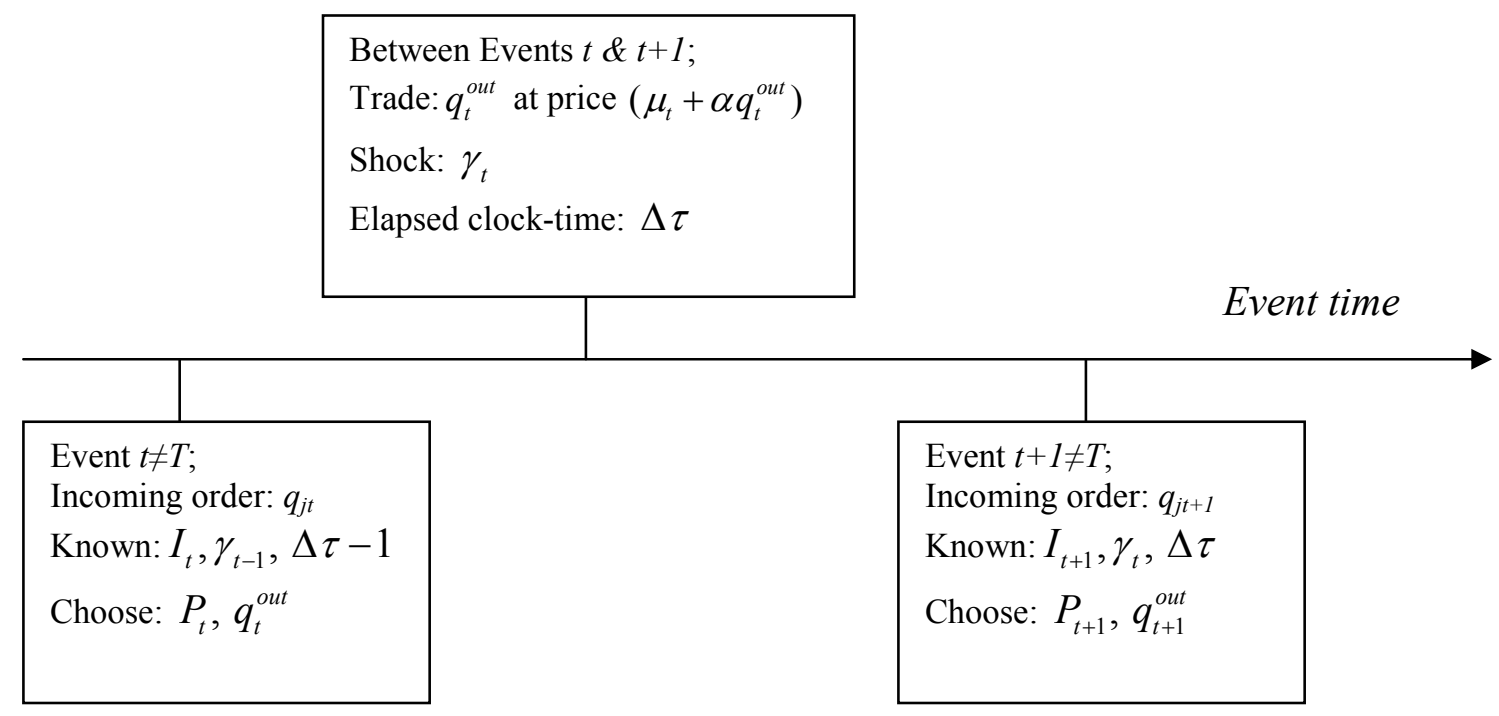

The figure above describes the timing of the model. At every event:

1. if $t \neq T$, the dealer knows her current inventory (denoted $I_{t}$ ), and a new incoming trade (one source of information for updating priors) occurs. The incoming quantity is $q_{j t}$.

2. The dealer decides her price (denoted by $P_{t}$ ) and plans her outgoing trade (denoted by $q_{t}^{\text {out }}$ ). These are the alternate methods available for offsetting inventory disturbances caused by the incoming trade.

3. Between events, the dealer executes the planned outgoing trade $\left(q_{t}^{\text {out }}\right)$, and faces a quantity shock, (denoted by $\gamma_{t}$ ). This is another source of information for updating priors.

4. In addition, the dealer observes time elapsed between trades (denoted by $\Delta \tau$ ).

5. At the next event $(t+1)$, the dealer uses the new incoming trade $q_{j t+1}$ as well as the quantity shock between trades and the time elapsed between trades to update priors on the evolution of the asset value, and set prices. 
Figure 2. Daily Cumulative Incoming Unexpected Order Flow versus Price

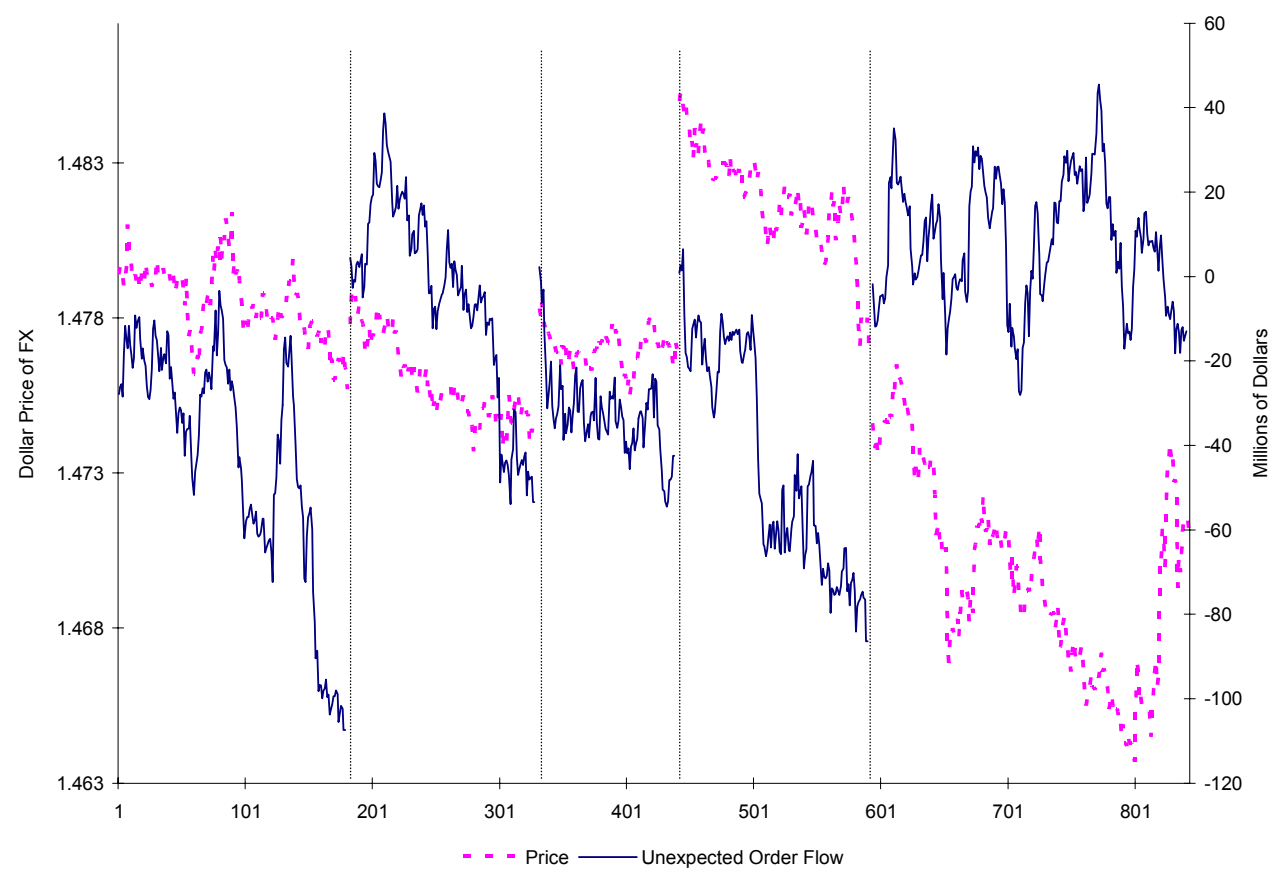

Figure 2 superimposes price on cumulative incoming unexpected order flow, August 3-7, 1992.

Figure 3. Daily Cumulative Inventory Shocks versus Price

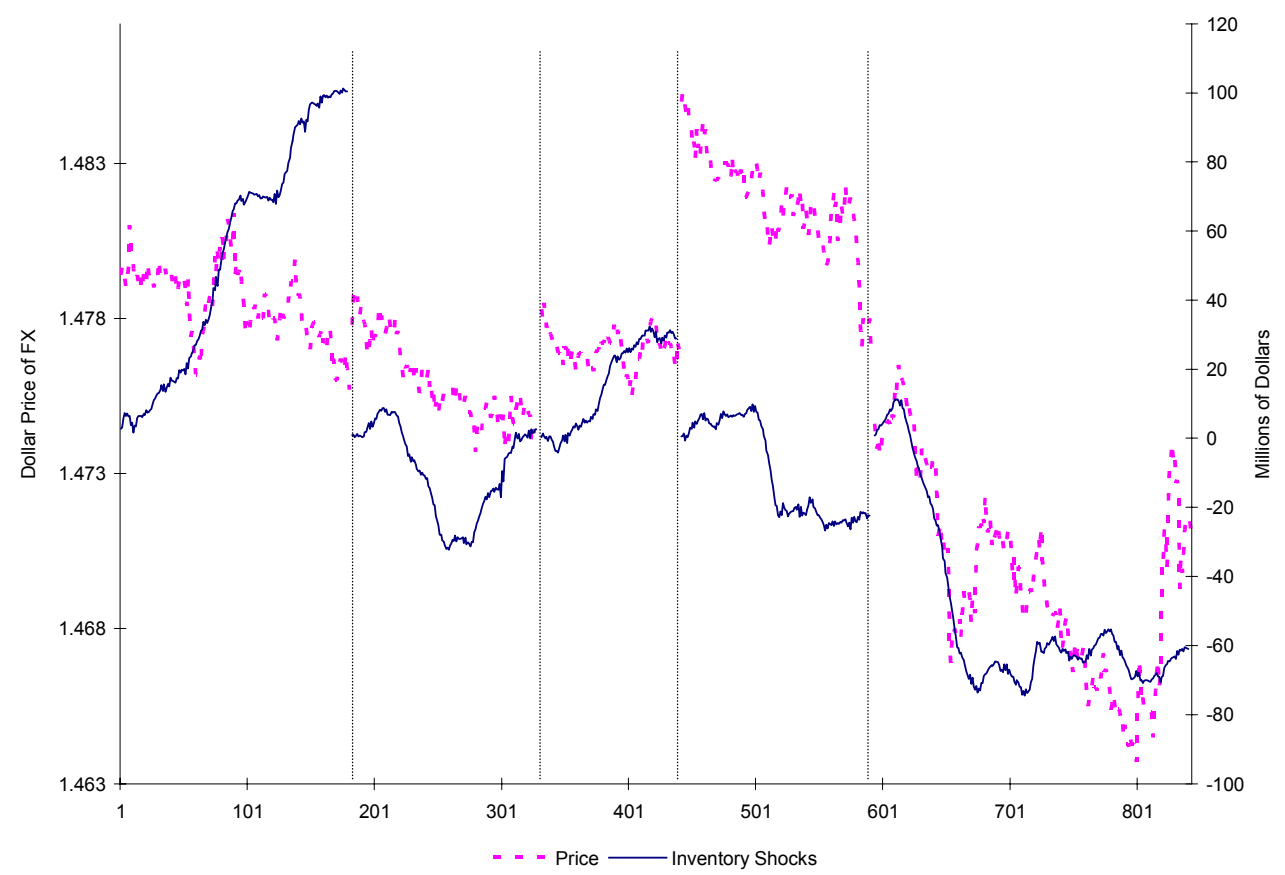

Figure 3 superimposes price on cumulative inventory shocks, August 3-7, 1992. 
Table 1. Daily Correlation of Order Flow Variables with Price

\begin{tabular}{lcccc}
\hline & Order Flow & $\begin{array}{c}\text { Unexpected } \\
\text { Order Flow }\end{array}$ & $\begin{array}{c}\text { Inventory } \\
\text { Shocks }\end{array}$ & $\begin{array}{c}\text { Mean Elapsed } \\
\text { Time* }\end{array}$ \\
\hline Monday & 0.83 & 0.83 & -0.54 & 1.77 \\
Tuesday & 0.69 & 0.71 & 0.58 & 1.86 \\
Wednesday & 0.53 & 0.48 & 0.03 & 2.44 \\
Thursday & 0.82 & 0.81 & 0.66 & 2.01 \\
Friday & -0.03 & -0.02 & 0.71 & 1.31 \\
\hline
\end{tabular}

Table 1 shows the daily correlation between price and the order flow variable used to update priors. The first column shows incoming unexpected order flow and the second inventory shocks correlations for each day, August 3-7, 1992. The last column shows daily mean elapsed intertransaction time.

* Reporting errors imply mean absolute value transaction time.

Table 2. Model Solutions and Estimable Equations

\begin{tabular}{|c|c|c|}
\hline Model Solution & Empirical Implementation & $\begin{array}{c}\text { Parameters } \\
\text { Recovered }\end{array}$ \\
\hline$I^{\prime}=I+\beta\left(I-I^{d}\right)+\left(\frac{(1+\beta)}{2 \alpha}\right) x$ & $I_{t+1}=a_{0}+a_{1} I_{t}+\varepsilon_{1, t}$ & $\begin{array}{l}\hat{I}^{d}=\frac{\hat{a}_{0}}{1-\hat{a}_{1}} \\
\hat{a}_{1}=1+\beta\end{array}$ \\
\hline$q^{\text {out }}=\left(A_{1} / A_{1}-\alpha\right)\left[-\left(I-I^{d}\right)+\delta(\mu-p)+x\right]$ & $\begin{array}{l}\left(q_{t}^{\text {out }}+\gamma_{t}\right)=b\left(-\left(I_{t}-\hat{I}^{d}\right)+q_{j t}\right)+\varepsilon_{2, t} \\
\text { with } \quad\left(q_{t}^{\text {out }}+\gamma_{t}\right) \equiv I_{t+1}-I_{t}+q_{j t}\end{array}$ & $\begin{array}{l}\hat{q}_{t}^{\text {out }}=\hat{b}\left(-\left(I_{t}-\hat{I}^{d}\right)+q_{j t}\right. \\
\hat{\gamma}_{t}=\hat{\varepsilon}_{2, t} \\
\hat{b}=\left(A_{1} / A_{1}-\alpha\right)\end{array}$ \\
\hline $\begin{array}{l}\Delta p=\psi_{1} \eta s_{t}^{*}+A_{1}(1+\beta)\left(q_{t-1}^{\text {out }}+\gamma_{t-1}-q_{j t-1}\right. \\
+\psi_{2}(1-\eta) \kappa\left(\gamma_{t-1}\right)+\frac{\delta A_{1}(1+\beta)+\alpha}{2 \alpha \delta} \Delta x_{t}\end{array}$ & $\begin{array}{l}\Delta p_{t}=c_{0}\left(1-\eta_{t}\right)+\eta c_{1} s_{t}^{*}+c_{2}\left(q_{t-1}^{\text {out }}+\gamma_{t-1}-q_{j t-1}\right) \\
+c_{3}\left(1-\eta_{t}\right) \gamma_{t-1}+c_{4} D_{t}+c_{5} D_{t-1}+\varepsilon_{3 t} \\
\text { with } q_{t-1}^{\text {out }}+\gamma_{t-1}-q_{j t-1} \equiv I_{t}-I_{t-1} \\
\text { and } \kappa\left(\gamma_{t-1}\right)=\alpha_{0}+\alpha_{1} \gamma_{t-1}\end{array}$ & $\begin{array}{l}\hat{c}_{1}, \hat{c}_{2}, \hat{c}_{3}, \hat{c}_{4} \\
\hat{c}_{2}=A_{1}(1+\beta)\end{array}$ \\
\hline \multicolumn{3}{|c|}{ Liquidity Cost Parameters } \\
\hline$\delta=\left(\left(1-\hat{a}_{1}-\hat{b}\right) / \hat{c}_{2}(\hat{b}-1)\right)$ & $\alpha=\left(\begin{array}{c}\hat{c}_{2}(\hat{b}-1) \\
)\end{array}\right.$ & \\
\hline
\end{tabular}

Table 2 compares the algebraic solution to the model (in the first column) with the estimable equations these imply (in the second column). The final column shows the parameters recovered for economic interpretation. Row (1) shows inventory evolution, row (2) shows outgoing quantity, and row (3) shows price changes. The bottom shows how the structural parameters measuring the cost of liquidity are recovered from the estimates. 
Table 3. Price Change Equation

\begin{tabular}{|c|c|c|c|c|c|c|c|}
\hline & $C_{0}$ & $C_{1}$ & $c_{2}$ & $C_{3}$ & $C_{4}$ & $C_{5}$ & $A d j \cdot R^{2}$ \\
\hline \multirow[t]{2}{*}{ Full } & -1.98 & 2.51 & -0.98 & 4.33 & 12.45 & -9.06 & 0.21 \\
\hline & 0.39 & 0.00 & 0.00 & 0.02 & 0.00 & 0.00 & \\
\hline \multirow[t]{2}{*}{ No Fed } & -4.38 & 1.73 & -1.12 & 4.58 & 14.15 & -9.98 & 0.29 \\
\hline & 0.03 & 0.02 & 0.00 & 0.00 & 0.00 & 0.00 & \\
\hline
\end{tabular}

\section{Previous Estimates}

\begin{tabular}{cccccccc}
\multicolumn{6}{c}{$\Delta p_{t}=\beta_{0}+\beta_{1} q_{j t}+\beta_{2} I_{t}+\beta_{3} I_{t-1}+\beta_{4} D_{t}+\beta_{5} D_{t-1}+m a(1)$} \\
\hline \multirow{2}{*}{ Estimate } & $\beta_{0}$ & $\beta_{1}$ & $\beta_{2}$ & $\beta_{3}$ & $\beta_{4}$ & $\beta_{5}$ & Adj. $R^{2}$ \\
& -1.30 & 1.44 & -0.98 & 0.79 & 10.15 & -8.93 & 0.21 \\
& 0.99 & 0.00 & 0.00 & 0.00 & 0.00 & 0.00 &
\end{tabular}

Table 3 compares the non-linear regression estimates of the model presented here with estimates of inventory and asymmetric information effects in these data using previous models. The upper panel shows two sets of estimated parameters (with p-values in italics). The row labeled Full includes a $\$ 300$ million Fed intervention in the last 5 percent of the sample, August 7, 1992. The row labeled No Fed excludes this intervention. The bottom panel reproduces the previous estimation of Lyons (1995). All estimates multiplied by $10^{5}$.

\section{Table 4. Model Estimates}

\begin{tabular}{|c|c|c|c|c|c|c|}
\hline & $b$ & $A d j . R^{2}$ & $a_{0}$ & $a_{1}$ & $A d j . R^{2}$ & $I^{*}$ \\
\hline Full & $\begin{array}{c}0.243 \\
0.00\end{array}$ & 0.23 & $\begin{array}{c}0.214 \\
0.37\end{array}$ & $\begin{array}{c}0.900 \\
0.00\end{array}$ & 0.81 & 2.14 \\
\hline No Fed & $\begin{array}{c}0.239 \\
0.00\end{array}$ & 0.23 & $\begin{array}{c}0.240 \\
0.37\end{array}$ & $\begin{array}{c}0.904 \\
0.00\end{array}$ & 0.81 & 2.50 \\
\hline
\end{tabular}

Table 4 shows the linear regression estimates from the auxiliary regressions in rows (1) and (2) of Table 2, August 3-7, 1992. P-values obtained using Huber/White robust standard errors are in italics below point estimates. In the left panel, the estimate $\hat{b}$ represents the proportion of the undesired inventory that the dealer trades out. In the right panel, $I *$ indicates the desired inventory position. 
Table 5. Cost of Liquidity

Incoming Liquidity: $q_{j t}=\delta\left(v_{t}-p_{t}\right)+X_{t} ; \quad$ Outgoing Liquidity: $q_{t}^{\text {out }}\left(\mu+\alpha q_{t}^{\text {out }}\right)$;

\begin{tabular}{lccccccc}
\hline & \multicolumn{5}{c}{ Incoming Cost of \$10 M } & & $\begin{array}{c}\text { Cost } \\
\text { Sample }\end{array}$ \\
\hline \multirow{2}{*}{ Full } & $\boldsymbol{N}$ & Pips & Dollars & Percent & $\alpha$ & Ratio \\
\multirow{2}{*}{ No Fed } & 73408.72 & 1.36 & $\$ 923.03$ & $0.0092 \%$ & 1.43 & 10.5 \\
\hline
\end{tabular}

Table 5 shows the structural parameter values recovered from the coefficient estimates. $\delta$ measures the change in the incoming order from changing the price (in millions of dollars). The Incoming Cost of $\$ 10$ $M$ columns measure the cost of attracting a $\$ 10$ million order (standard size) in: pips (DM0.0001), US dollars, and dollar cost as a percent of the $\$ 10$ million order. $\alpha$ measures the price impact of augmenting the outgoing order by $\$ 1$ million in pips. The final column measures the ratio of costs of dealing \$1 million through outgoing order flow (numerator) versus incoming order flow (denominator).

Table 6. Incoming versus Outgoing Order Flow

\begin{tabular}{cccccc}
\hline & Daily Avg. & \multicolumn{2}{c}{ Size (Abs. Val.) } & \multicolumn{2}{c}{ Daily Volume Ratio } \\
Trades & No. & Median & Average & Median & Average \\
\hline Incoming & 170 & 2.50 & 3.80 & 8.6 & 9.9 \\
Outgoing & 20 & 2.48 & 3.26 & & \\
\hline
\end{tabular}

Table 6 shows the observed trades that the dealer made, August 3-7, 1992. Incoming refers to trades that the dealer made when contacted by others. Outgoing refers to trades that initiated by contacting others. Size is the absolute value of the order size; the median and average are given. Daily volume ratio gives the ratio of the average incoming daily volume (average or median size times average number of trades) to the average outgoing volume. These do not include brokered trade, for which the initiator of the trade is unknown. 
Table 7. Cost of Intervention

\begin{tabular}{|c|c|c|c|c|}
\hline \multirow[t]{3}{*}{ (1) } & $(2)$ & (3) & \multirow{2}{*}{\multicolumn{2}{|c|}{$\begin{array}{l}\text { (4) } \\
\text { Orders induced for an intervention- } \\
\text { equivalent price change }\end{array}$}} \\
\hline & \multicolumn{2}{|c|}{$\begin{array}{l}\text { Fed moves this many pips per } \$ 100 \mathrm{M} \\
\qquad(\$ 300 \mathrm{M})\end{array}$} & & \\
\hline & To Closing & To High & To Closing & To High \\
\hline \multicolumn{5}{|l|}{ (Intervention Start) } \\
\hline \multirow[t]{2}{*}{ * 12:32 PM } & -3.00 & 6.67 & $-\$ 55.13$ & $\$ 122.51$ \\
\hline & $-(9.0)$ & $(20.0)$ & & \\
\hline \multicolumn{5}{|l|}{ (Other Studies) } \\
\hline \multicolumn{2}{|c|}{ Evans \& Lyons (1999) } & 5 & & \\
\hline \multicolumn{2}{|c|}{ Dominguez \& Frankel (1993) } & 8 & & \\
\hline \multicolumn{5}{|c|}{ (Other possible start times) } \\
\hline \multirow[t]{2}{*}{ 12:02 PM } & 19.33 & 29.00 & $\$ 355.27$ & $\$ 532.90$ \\
\hline & $(58.0)$ & (87.0) & & \\
\hline $12: 26 \mathrm{PM}$ & $\begin{array}{l}15.33 \\
(46.0)\end{array}$ & $\begin{array}{l}25.00 \\
(75.0)\end{array}$ & $\$ 281.76$ & $\$ 459.40$ \\
\hline
\end{tabular}

Table 7 shows cost comparisons for the $\$ 300$ million Fed intervention on August 7, 1992. The exact start time and sequence of the intervention is unknown. Column (1) lists three possible times. Columns (2) and (3) show the price change in pips (DM 0.0001) that a $\$ 100$ million Fed purchase induces from the start of the intervention to the closing price (2), or high price (3). Columns (4) \& (5) show how many millions of dollars the dealer could induce by changing her price the number of pips as the $\$ 300$ million intervention price change.

* Wall Street Journal, August 10, 1992: "The Federal Reserve Bank of New York moved to support the U.S. currency... as the dollar traded at 1.4720." This is the most precise documentation available of the intervention start, and that price corresponds to $12: 32 \mathrm{pm}$. Other times selected because of reports of a mid-day start, and because between 12:26 and 12:32 pm, the price jumped 36 pips, suggesting a possible intervention start there. 


\section{APPENDIXES}

\section{Model Solution}

\section{Inventory Carrying Cost}

From equations (2) and (3) the variance of the dealer's portfolio is

$$
\sigma_{W_{t}}^{2}=\sigma_{V}^{2} I_{t}^{2}+\sigma_{y}^{2}+2 I_{t} \sigma_{v y} \text {. }
$$

Add and subtract $\left(\frac{\sigma_{v y}}{\sigma_{v}^{2}}\right)^{2}$ into (11) to get:

$$
c_{t}=\omega\left[\sigma_{y}^{2}-\left(\frac{\sigma_{v y}}{\sigma_{v}^{2}}\right)^{2}+\sigma_{V}^{2} I_{t}^{2}+2 I_{t} \sigma_{v y}+\left(\frac{\sigma_{v y}}{\sigma_{v}^{2}}\right)^{2}\right]=\omega\left[\left(\sigma_{y}^{2}-\left(\frac{\sigma_{v y}}{\sigma_{v}^{2}}\right)^{2}\right)+\sigma_{v}^{2}\left(I_{t}-\frac{-\sigma_{v y}}{\sigma_{v}^{2}}\right)^{2}\right]
$$

Which is the right-hand-side of (11) with coefficients:

$$
I^{d}=\left(\frac{-\sigma_{v y}}{\sigma_{v}^{2}}\right) \quad \phi_{1}=\sigma_{v}^{2} \quad \phi_{0}=\sigma_{y}^{2}-\left(\frac{\sigma_{v y}}{\sigma_{v}^{2}}\right)^{2} .
$$

\section{Dealer's Beliefs}

Given market demand $q_{j t}$, the dealer creates a statistic based on the intercept of the demand curve, which is independent of her price. Denote this statistic as $D_{t}$.

$$
D_{t}=q_{j t}+\delta p_{t}=\delta\left(v_{t}-p_{t}\right)+X_{t}+\delta p_{t}=\delta v_{t}+X_{t} .
$$

From the signal of market demand $D_{t}$ the dealer forms two statistics. The first is an innovation in the full information value of the risky asset, which shall be denoted as $s_{t}$. The second is a signal of the liquidity demand, which is denoted as (lower case) $x_{t}$, and will depend on the estimate of full information value, $\mu_{t}$.

$$
\begin{gathered}
w_{t}=\delta^{-1} D_{t}=v_{t}+\frac{X_{t}}{\delta} ; \quad E\left[w_{t}\right]=v_{t} \\
x_{t}=D_{t}-\delta \mu_{t}, \quad E\left[x_{t}\right]=X_{t} .
\end{gathered}
$$

Consistent with rational expectations, assume that the dealer's previous estimate, $\mu_{t-1}$ is the steady state distribution over the true asset value $v_{t}$, and that the variance of $\mu_{t}$ is proportional to the variance of $w_{t}$. Hence, one can write $\sigma_{\mu}^{2}=\Omega \sigma_{w}^{2}$. Given the variance of $w_{t}$, form a signal to noise ratio given by:

$$
\Upsilon=\frac{\sigma_{v}^{2}}{\sigma_{w}^{2}}, \text { with } \sigma_{w}^{2}=\delta^{-2} \sigma_{x}^{2}
$$

The dealer uses the recursive updating of a Kalman filter to form the expectations over $v_{t}$. This implies that she updates the prior belief $\mu_{t-1}$ using the current order flow $w_{t}$. The resulting posterior, $\mu_{t}$, converges to a steady-state distribution whose time varying mean is an unbiased estimate of the true value of $v_{t}$. The recursive equations to generate this estimate are given by: 


$$
\Omega=\frac{-\Upsilon+\sqrt{\Upsilon^{2}+4 \Upsilon}}{2},
$$

Hence, if the dealer had only information based on the incoming order, she would use the following estimate, which is denoted as $\mu_{t}^{Z}$, as the estimate of $v_{t}$ :

$$
\mu_{t}^{Z}=\Omega w_{t}+(1-\Omega) \mu_{t-1} .
$$

Note, however, that the dealer also receives information for updating $\mu_{t-1}$ through a linear function of the inventory shock which is denoted by $\kappa\left(\gamma_{-1}\right)$. Given $\kappa\left(\gamma_{-1}\right)$, an unbiased estimate of $v_{t}$ is given by:

$$
\mu_{t}^{\gamma}=\Omega\left[\mu_{t-1}+\kappa\left(\gamma_{t-1}\right)\right]+(1-\Omega) \mu_{t-1}=\mu_{t-1}+\Omega \kappa\left(\gamma_{t-1}\right),
$$

where the same Kalman filter algorithm as defined above is used. Hence there are two signals of $v_{t}$ at the time of setting the price. Given the assumption, the variance of $\mu_{t}^{\gamma}$ is a linear function of the variance of $\mu_{t}^{Z}$. That is,

$$
\operatorname{var}\left(\mu_{t}^{Z}\right)=\sigma_{Z}^{2}, \quad \operatorname{var}\left(\mu_{t}^{\gamma}\right)=\sigma_{Z}^{2} * \Delta \tau
$$

where $\Delta \tau$ is the elapsed clock time between incoming order $(t-1)$ and $t$. The optimal signal for the dealer is then:

$$
\mu_{t}=\eta \mu_{t}^{Z}+(1-\eta) \mu_{t}^{\gamma}=\eta\left[\Omega w_{t}+(1-\Omega) \mu_{t-1}\right]+(1-\eta)\left[\mu_{t-1}+\Omega \kappa\left(\gamma_{t-1}\right)\right] .
$$

with $\eta=(\Delta \tau / 1+\Delta \tau)$. Now grouping and rearranging:

$$
\mu_{t}-\mu_{t-1}=\eta \Omega\left(w_{t}-\mu_{t-1}\right)+(1-\eta) \Omega \kappa\left(\gamma_{t-1}\right)=\eta \Omega\left(\delta^{-1} D_{t}-\mu_{t-1}\right)+(1-\eta) \Omega \kappa\left(\gamma_{t-1}\right)
$$

Since $w_{t}=\delta^{-1} D_{t}=v_{t}+\frac{X_{t}}{\delta}$

$$
\mu_{t}-\mu_{t-1}=\eta \Omega\left(\delta^{-1}\left(q_{j t}+\delta p_{t}\right)-\mu_{t-1}\right)+(1-\eta) \Omega \kappa\left(\gamma_{t-1}\right)
$$

Add and subtract $\delta \mu$ to get:

$$
\mu_{t}-\mu_{t-1}=\eta \Omega \delta^{-1}\left[q_{j t}-\delta\left(\mu_{t}-p_{t}\right)+\delta\left(\mu_{t}-\mu_{t-1}\right)\right]+(1-\eta) \Omega \kappa\left(\gamma_{t-1}\right)
$$

Solving for $\left(\mu_{t}-\mu_{t-1}\right)$ yields,

$$
\left(\mu_{t}-\mu_{t-1}\right)[1-\Omega \eta]=\eta \Omega \delta^{-1}\left[q_{j t}-\delta\left(\mu_{t}-p_{t}\right)\right]+(1-\eta) \Omega \kappa\left(\gamma_{t-1}\right)
$$

Which gives the final relationship for the updating:

$$
\left(\mu_{t}-\mu_{t-1}\right)=\xi_{1} s_{t}+\xi_{2} \kappa\left(\gamma_{-1}\right)
$$

Where $s_{t}=q_{j t}-\delta\left(\mu_{t}-p_{t}\right)$ is the unexpected order flow, and

$$
\xi_{1}=\frac{\eta \Omega}{\delta(1-\Omega \eta)} \quad \& \quad \frac{\partial \xi_{1}}{\partial \eta}>0 ; \quad \xi_{2}=\frac{(1-\eta) \Omega}{\delta(1-\Omega \eta)} \quad \& \quad \frac{\partial \xi_{2}}{\partial \eta}<0
$$

Hence, $\xi_{1}$ and $\xi_{2}$ are inversely related with respect to $\eta$, and as intertransaction time is longer, more weight is placed on the unexpected incoming order flow signal $s_{t}$. Here, $\kappa\left(\gamma_{t-1}\right)$ is assumed to be some simple linear function: $\kappa\left(\gamma_{t-1}\right)=\omega_{0}+\omega_{1} \gamma_{t-1}$, where $\omega_{0}$ may be assumed zero if desired. 


\section{The Dealer's Problem}

The dealer's problem is reproduced here:

$J\left(I_{t}, x_{t}, \mu_{t}, K_{t}\right)=\max _{p_{t}, q_{t}^{\text {out }}} E\left\{(1-\rho)\left[\tilde{v}_{t} I_{t}+K_{t}-c_{t}\right]+\rho J\left(\tilde{I}_{t+1}, \tilde{x}_{t+1}, \tilde{\mu}_{t+1}, \tilde{K}_{t+1}\right)\right\}$,

subject to the following evolution constraints:

$$
\begin{gathered}
E\left[\tilde{I}_{t+1} \mid \Phi_{t}^{i}\right]=I_{t}-\delta\left(\mu_{t}-p_{t}\right)-x_{t}+q_{t}^{\text {out }}, \\
E\left[\tilde{x}_{t+1} \mid \Phi_{t}^{i}\right]=0, \\
E\left[\tilde{\mu}_{t+1} \mid \Phi_{t}^{i}\right]=\mu_{t}, \\
E\left[\tilde{K}_{t+1} \mid \Phi_{t}^{i}\right]=K_{t}+p_{t} \delta\left(\mu_{t}-p_{t}\right)+p_{t} x_{t}-\left(\mu_{t}+\alpha q_{t}^{\text {out }}\right) q_{t}^{\text {out }}-c_{t},
\end{gathered}
$$

For expositional simplicity, in what follows the expectation operators on the evolution equations and the time subscripts are dropped, and a forward lag is denoted by a 'superscript.' The first order conditions are given by:

$$
\begin{gathered}
p: \delta E\left[J_{I}\left(I^{\prime}, x^{\prime}, \mu^{\prime}, K^{\prime}\right)\right]+(\delta \mu-2 \delta p+x) E\left[J_{K}\left(I^{\prime}, x^{\prime}, \mu^{\prime}, K^{\prime}\right)\right]=0, \\
q^{\text {out }}: E\left[J_{I}\left(I^{\prime}, x^{\prime}, \mu^{\prime}, K^{\prime}\right)\right]-\left(\mu+2 \alpha q^{\text {out }}\right) E\left[J_{K}\left(I^{\prime}, x^{\prime}, \mu^{\prime}, K^{\prime}\right)\right]=0 .
\end{gathered}
$$

Substituting (52) into (51), and assuming for now that $E\left[J_{K}\left(I^{\prime}, x^{\prime}, \mu^{\prime}, K^{\prime}\right)\right] \neq 0$ (I confirm this later), price is:

$$
p=\mu+\frac{x}{2 \delta}+\alpha q^{\text {out }}
$$

Denote from here on the value function without its arguments for notational simplicity, maintaining the convention that $J\left(^{\prime}\right)$ is the forward lag of $J()$. Furthermore, in what follows a subscript denotes the derivative of the function with respect to that argument. The envelope conditions for this problem are:

$$
\begin{gathered}
J_{I}()=(1-\rho) \mu+\rho E\left[J_{I}\left({ }^{\prime}\right)\right]-2 \omega \phi_{1}\left(I-I^{d}\right)\left[(1-\rho)+\rho E\left[J_{K}(')\right]\right] \\
J_{x}()=-\rho\left(E\left[J_{I}\left({ }^{\prime}\right)\right]-p E\left[J_{K}(')\right]\right) ; \\
J_{\mu}()=(1-\rho) I-\delta \rho E\left[J_{I}(')\right]+\rho E\left[J_{\mu}\left({ }^{\prime}\right)\right]+\rho\left(\delta p-q^{\text {out }}\right) E\left[J_{K}(')\right] ; \\
J_{K}()=(1-\rho)+\rho E\left[J_{K}(')\right] ;
\end{gathered}
$$

Based on the envelope conditions, it is conjectured that the value function takes on the functional form:

$$
\tilde{J}(I, x, \mu, K)=A_{0}+\mu I+K+A_{1}\left(I-I^{d}\right)^{2}+A_{2} x\left(I-I^{d}\right)+A_{3} x^{2} .
$$

Using the conjecture, and the evolution equations, taking the derivatives with respect to $I$ and $K$ updating:

$$
\begin{gathered}
E\left[\tilde{J}_{I}(')\right]=E\left[\mu^{\prime}+2 A_{1}\left(I^{\prime}-I^{d}\right)+A_{2} x^{\prime}\right]=\mu+2 A_{1}\left(I^{\prime}-I^{d}\right) . \\
E\left[\tilde{J}_{K}(')\right]=E[1]=1 .
\end{gathered}
$$

Plugging (59) and (60) into (52) yields the optimal outgoing quantity:

$$
\frac{A_{1}}{\alpha}\left(I^{\prime}-I^{d}\right)=q^{\text {out }} \text {. }
$$

Substituting (61) into (53) for $q^{\text {out }}$ yields the pricing equation: 


$$
p=\mu+A_{1}\left(I^{\prime}-I^{d}\right)+\frac{x}{2 \delta} .
$$

Taking the evolution equation for inventory, (47), one can substitute (62) in for $p$ and solve for $I^{\prime}$ to get:

$$
I^{\prime}=I+\beta\left(I-I^{d}\right)+\left(\frac{(1+\beta)}{2 \alpha}\right) x,
$$

with

$$
\beta=\left(\frac{A_{1}(1+\delta \alpha)}{\alpha-A_{1}(1+\delta \alpha)}\right) \Leftrightarrow A_{1}=\left(\frac{\beta \alpha}{(1+\beta)(1+\delta \alpha)}\right) .
$$

Given the inventory evolution of (63), one can solve for the optimal pricing policy function:

$$
p=\mu+A_{1}(1+\beta)\left(I-I^{d}\right)+\left(\frac{\delta A_{1}(1+\beta)+\alpha}{2 \alpha \delta}\right) x .
$$

Taking first differences of (65), and substituting in:

$$
\Delta p=\Delta \mu-A_{1}(1+\beta) Z_{-1}+A_{1}(1+\beta)\left(q_{-1}^{\text {out }}+\gamma_{-1}\right)+\left(\frac{\delta A_{1}(1+\beta)+\alpha}{2 \alpha \delta}\right) \Delta x .
$$

Substituting the relationship for the updating of the $\mu_{t}$ given by (44) yields:

$$
\Delta p_{t}=\psi_{1} \eta s_{t}^{*}+A_{1}(1+\beta)\left(q_{t-1}^{\text {out }}+\gamma_{t-1}-q_{j, t-1}\right)+\psi_{2}(1-\eta) \gamma_{t-1}+\left(\frac{\delta A_{1}(1+\beta)+\alpha}{2 \alpha \delta}\right) \Delta x
$$

Next the conjectured functional form of (58) is confirmed. Begin by taking the envelope condition for $x,(55)$, and solve for coefficients $\mathrm{A}_{2}$ and $\mathrm{A}_{3}$ of the conjectured functional form's derivative, which is:

$$
\tilde{J}_{x}=2 A_{2} x+A_{3} \varepsilon
$$

Substituting the optimal policy functions into (55), as well as the updated derivatives of the conjectured functional form which are given by (59) and (60) yields:

$A_{2}=-\rho A_{1}(1+\beta), \quad A_{3}=-\rho\left(A_{1}(1+\beta) \delta+\alpha\right) / 4 \delta \alpha$. Continuing, the envelope condition on $I$ in $(58)$ can be solved with the conjectured functional form's derivative, which is given in (59). This yields $A_{1}=\left[\left(-\omega \phi_{1}\right) / 1-\rho(1+\beta)\right]$. An economically sensible solution requires $A_{1}<0$, hence, using the definition for $A_{l}$, it is required that:

$$
\beta+\frac{\omega \phi(1+\beta)(1+\delta \alpha)}{1-\rho(1+\beta)}=0 .
$$

This implies $\beta \in(-1,0)$. As $\beta \rightarrow-1$, the right-hand-side of (69) goes to negative one. As $\beta \rightarrow 0$, the right-hand-side of (69) is positive. Hence, since (69) is a continuous function, by the Mean Value Theorem $\exists \beta \in(-1,0) \therefore$ (69) holds. 


\section{FURTHER ESTIMATION DETAILS}

\section{Derivation of Liquidity Cost Parameters}

$\hat{a}_{1}=1+\beta ; \quad \hat{b}=\frac{A_{1}}{A_{1}-\alpha} ; \quad \hat{c}_{2}=A_{1}(1+\beta) ; \quad \beta=\frac{A_{1}(1+\delta \alpha)}{\alpha-A_{1}(1+\delta \alpha)}$

$\alpha$ :

$\left(\frac{1}{\hat{b}}\right)\left(\frac{\hat{c}_{2}}{\hat{a}_{1}}\right)=\left(A_{1}-\alpha\right)$

$\left(\frac{\hat{c}_{2}}{\hat{a}_{1}}\right)-\left(\frac{1}{\hat{b}}\right)\left(\frac{\hat{c}_{2}}{\hat{a}_{1}}\right)=\frac{\hat{c}_{2}(\hat{b}-1)}{\hat{a}_{1} \hat{b}}=\hat{\alpha}$.

$\delta$ :

$\hat{a}_{1}=1+\beta=\frac{\alpha}{\alpha-A_{1}(1+\delta \alpha)} \Leftrightarrow \frac{1}{\hat{a}_{1}}=\frac{\alpha-A_{1}(1+\delta \alpha)}{\alpha}$,

$\left(\frac{1}{\hat{a}_{1}}\right)\left(\frac{\hat{c}_{2}(\hat{b}-1)}{\hat{a}_{1} \hat{b}}\right)=(\hat{\alpha})\left(\frac{\alpha-A_{1}(1+\delta \alpha)}{\alpha}\right)=\alpha-A_{1}(1+\delta \alpha)$,

$\left(\frac{\hat{c}_{2}(\hat{b}-1)}{\hat{a}_{1} \hat{b}}\right)-\left(\frac{1}{\hat{a}_{1}}\right)\left(\frac{\hat{c}_{2}(\hat{b}-1)}{\hat{a}_{1} \hat{b}}\right)=\left(\frac{\hat{c}_{2}(\hat{b}-1)}{\hat{a}_{1} \hat{b}}\right)\left(1-\frac{1}{\hat{a}_{1}}\right)=\alpha-\left(\alpha-A_{1}(1+\delta \alpha)\right)$,

$\left(\frac{\hat{c}_{2}(\hat{b}-1)\left(\hat{a}_{1}-1\right)}{\hat{a}_{1}^{2} \hat{b}}\right)=A_{1}(1+\delta \alpha)$,

$\left(\frac{\hat{a}_{1}}{\hat{c}_{2}}\right)=\frac{1}{A_{1}}$,

$\left(\frac{\hat{c}_{2}(\hat{b}-1)\left(\hat{a}_{1}-1\right)}{\hat{a}_{1}^{2} \hat{b}}\right)\left(\frac{\hat{a}_{1}}{\hat{c}_{2}}\right)=\left(\frac{(\hat{b}-1)\left(\hat{a}_{1}-1\right)}{\hat{a}_{1} \hat{b}}\right)=(1+\delta \alpha)$,

$\left(\frac{(\hat{b}-1)\left(\hat{a}_{1}-1\right)}{\hat{a}_{1} \hat{b}}-1\right)=\delta \alpha, \quad \frac{1}{\alpha}=\frac{\hat{a}_{1} \hat{b}}{\hat{c}_{2}(\hat{b}-1)}$,

$\left(\frac{\hat{a}_{1} \hat{b}}{\hat{c}_{2}(\hat{b}-1)}\right)\left(\frac{(\hat{b}-1)\left(\hat{a}_{1}-1\right)-\hat{a}_{1} \hat{b}}{\hat{a}_{1} \hat{b}}\right)=\left(\frac{1-\hat{b}-\hat{a}_{1}}{\hat{c}_{2}(\hat{b}-1)}\right)=\delta$;

\section{Linear Approximations to the Model}

The following linear approximations to the model were also estimated. The parameter estimates obtained were used to initialize the non-linear least squares, as were zeros. Sup-F tests for multiple structural breaks were also run on these equations and were generally not found. The estimates were consistent with those found here and are available from the author upon request. Below, $Z_{t}$ represents the observed incoming order, $q_{j t}$.

1. $\Delta p_{t}=\beta_{0}+\beta_{1}(1-\eta) s_{t}+\beta_{2}\left(\hat{q}_{t-1}^{\text {out }}-Z_{t-1}\right)+\beta_{3}(\eta) \hat{\gamma}_{t-1}+\beta_{4} D_{t}+\beta_{5} D_{t-1}+\varepsilon_{t}$

2. $\Delta p_{t}=\beta_{0}+\beta_{1}(1-\eta) Z_{t}+\beta_{2}\left(\hat{q}_{t-1}^{\text {out }}-Z_{t-1}\right)+\beta_{3}(\eta) \hat{\gamma}_{t-1}+\beta_{4} D_{t}+\beta_{5} D_{t-1}+\varepsilon_{t}$

3. $\Delta p_{t}=\beta_{0}+\beta_{1}(1-\eta) s_{t}+\beta_{2} Z_{t-1}+\beta_{3}(\eta) \gamma_{t-1}+\beta_{4} D_{t}+\beta_{5} D_{t-1}+\varepsilon_{t}$

4. $\Delta p_{t}=\beta_{0}+\beta_{1}(1-\eta) Z_{t}+\beta_{2} Z_{t-1}+\beta_{3}(\eta) \gamma_{t-1}+\beta_{4} D_{t}+\beta_{5} D_{t-1}+\varepsilon_{t}$

5. stage 1: $\Delta p_{t}=\beta_{0}^{\prime}+\beta_{1}^{\prime}(1-\eta) s_{t}+\beta_{2}^{\prime}\left(\hat{q}_{t-1}^{\text {out }}-Z_{t-1}\right)+\beta_{3}^{\prime} \eta \hat{\gamma}_{t-1}+\beta_{4}^{\prime} D_{t}+\beta_{s}^{\prime} D_{t-1}+\varepsilon_{t}$ stage 2: $\Delta p_{t}=\beta_{0}+\beta_{1}(1-\eta) s_{t}+\beta_{2}\left(\hat{q}_{t-1}^{\text {out }}-Z_{t-1}\right)+\beta_{3}\left(\hat{\beta}_{2}^{\prime}+\hat{\beta}_{3}^{\prime} \eta\right) \hat{\gamma}_{t-1}+\beta_{4} D_{t}+\beta_{5} D_{t-1}+\varepsilon_{t}$ 


\section{Instrumental Variable Selection}

It is difficult to find a good instrument for $\gamma$ since it is a financial market shock. The instruments chosen were a lead and a lag. Using only a lag, or only a lead, lowers the correlation of the instrument with the variable.

$$
\gamma_{t}=(L(1)+L(-1)) \gamma_{t} \text {. }
$$




\section{REFERENCES}

Admati, A., and P. Pfleiderer, 1988, "A Theory of Intraday Patterns: Volume and Price Variability," Review of Financial Studies, Vol. 1 (Spring), pp. 3-40.

Amihud, Y., and H. Mendelson, 1980, "Dealership Market: Marketmaking with Inventory," Journal of Financial Economics, Vol. 8 (March), pp. 31-53.

Andrews, D.W.K., 1993, “Testing for Parameter Instability and Structural Change with Unknown Change Point," Econometrica, Vol. 61 (July), pp. 821-56.

Bai, J. and P. Perron, 1998, "Estimating and Testing Linear Models with Multiple Structural Changes," Econometrica, Vol. 66 (January), pp. 47-78.

Bjonnes, G., and D. Rime, 2000, “FX Trading ... Live: Impact of New Trading Environments,” (unpublished; Oslo: Norwegian School of Management).

Blitz, James, 1992, “Dollar Below Intervention level,” Financial Times (London: August 11, 1992), p. 23.

Cao, H. H., M. D. D. Evans, and R. K. Lyons, 2002, "Inventory Information," (unpublished; Haas School of Business, University of California at Berkeley).

Dominguez, K., and J. Frankel, 1993a, "Does Foreign-Exchange Intervention Matter? The Portfolio Effect," American Economic Review, Vol. 83 (December), pp.1356-69.

—, $1993 \mathrm{~b}$, "Does Foreign-Exchange Intervention Work?” (Washington: Institute for International Economics).

Easley, D., and M. O'Hara, 1987, "Price, Trade Size, and Information in Securities Markets," Journal of Financial Economics, Vol. 19 (September), pp. 69-90.

— 1992, "Time and the Process of Security Price Adjustment," Journal of Finance, Vol. 47 (June), pp. 577-605.

Evans, M. D. D. and R. K. Lyons, 2002. "Order Flow and Exchange Rates Dynamics." Journal of Political Economy, Vol. 110 (February), pp. 170-180.

"US Fed Intervenes as Dollar Nears Low Against D-Mark," Financial Times (London: August 8, 1992), p.1.

Flood, R., and A. Rose, 1995, "Fixing Exchange Rates: A Virtual Quest for Fundamentals," Journal of Monetary Economics, Vol. 36 (December), pp 3-37. 
Flood, R., and M. Taylor, 1996, "Exchange Rate Economics: What's Wrong with the Conventional Macro Approach?" The Microstructure of Foreign Exchange Markets, ed. by J. Frankel, G. Galli, and A. Giovannini (Chicago: The University of Chicago Press), pp. 261-294.

Frankel, J., G. Galli, and A. Giovannini, 1996, The Microstructure of Foreign Exchange Markets, (Chicago: University of Chicago Press).

Frankel, J., and A. Rose, 1995, "Empirical Research on Nominal Exchange Rates," Handbook of International Economics, ed. By G. Grossman and K. Rogoff (Amsterdam: Elsevier Science) pp.1689-1729.

Froot, K. A., P. O'Connel, and M. Seasholes, 2001, “The Portfolio Flows of International Investors,” Journal of Financial Economics, Vol. 59 (February). pp.151-93.

Froot, K. A. and T. Ramadorai, 2001a, "The Information Content of International Portfolio Flows," (unplublished; Boston: Graduate School of Business, Harvard University).

— , 2001b, "Currency Returns, Institutional Investor Flows, and Exchange-rate Fundamentals," (unplublished; Boston: Graduate School of Business, Harvard University).

Glosten, L., and P. Milgrom, 1985, "Bid, Ask, and Transaction Prices in a Specialist Market with Heterogeneously Informed Agents," Journal of Financial Economics, Vol. 14 (March), pp. 71-100.

Hasbrouck, J., 1988, “Trades, Quotes, Inventories, and Information,” Journal of Financial Economics Vol. 22 (December), pp. 229-252.

- 1991a, Measuring the Information Content of Stock Trades," Journal of Finance, Vol. 46 (March), pp.179-207.

- 1991b, The Informativeness of Stock Trades: An Econometric Analysis," Review of Financial Studies, Vol.4 (No. 3), pp. 571-595.

Ho, T., and H. Stoll, 1981, "Optimal Dealer Pricing Under Transactions and Return Uncertainty,” Journal of Financial Economics, Vol. 9 (March), pp.47-73.

— 1983, “The Dynamics of Dealer Markets under Competition, “ Journal of Finance Vol. 38 (September), pp. 1053-74.

Ito, T., R. Lyons, and M. Melvin, 1998, "Is There Private Information in the FX Market? The Tokyo experiment," Journal of Finance, Vol. 53 (June), pp. 1111-30.

Kyle, A., 1985, "Continuous Auctions and Insider Trading," Econometrica, Vol. 53 (November), pp. 1315-35. 
Linton, Clifton, "Dollar Likely to Fall Though Banks May Try to Slow Currency's Descent," Wall Street Journal (New York: Aug 10, 1992), p. C13.

Lyons, R., 1995, "Tests of Microstructural Hypotheses in the Foreign Exchange Market," Journal of Financial Economics, Vol. 39 (October), pp. 321-51.

, 1996, "Optimal Transparency in a Dealer Market with an Application to Foreign Exchange,” Journal of Financial Intermediation, Vol. 5 (July) pp. 225-54.

—_ 1997, "A Simultaneous Trade Model of the Foreign Exchange Hot Potato," Journal of International Economics, Vol. 42 (May), pp. 275-98.

— 1998 , "Profits and Position Control: A Week of FX Dealing," Journal of International Money and Finance, Vol. 17 (February), pp. 97-115.

— 2001, The Microstructure Approach to Exchange Rates, (Cambridge and London: MIT Press).

Madhavan, A., and G. Sofianos, 1998, “An Empirical Analysis of NYSE Specialist Trading,” Journal of Financial Economics Vol. 48 (May), pp. 189-210.

Madhavan, A., and S. Smidt, 1991, "A Bayesian Model of Intraday Specialist Pricing," Journal of Financial Economics, Vol. 30 (November), pp. 99-134.

- 1993, "An Analysis of Daily Changes in Specialist Inventories and Quotations." Journal of Finance, Vol. 48 (December), pp.1595-1648.

Manaster, Steven; Mann, Steven C., 1996, "Life in the Pits: Competitive Market Making and Inventory Control," Review of Financial Studies Vol. 9 (Fall), pp. 953-75.

Meese, R., and K. Rogoff, 1983, "The Out-of-sample Failure of Empirical Exchange Rate Models," Exchange Rate and International Macro-economics, ed. by J. Frenkel (Chicago: University of Chicago Press).

Mello, A., 1996, Comment-Chapter 5. The Microstructure of Foreign Exchange Markets, ed. by J. Frankel, G. Galli, and A. Giovannini (Chicago: The University of Chicago Press).

O'Hara, M.; Oldfield, G. S., 1986 “The Microeconomics of Market Making," Journal of Financial and Quantitative Analysis, Vol. 21 (December), pp. 361-76.

Rime, D., 2000, "Private or public information in foreign exchange markets? An empirical analysis," (unpublished; Oslo: Norwegian School of Management). 
Romeu, R. B., 2001, “A Puzzle of Microstructure Market Maker Models,” (unpublished; College Park, Maryland: University of Maryland).

Stoll, Hans R., 1978, “The Supply of Dealer Services in Securities Markets, “ Journal of Finance Vol. 33 (September), pp. 1133-51.

Yao, J., 1998, "Market Making in the Interbank Foreign Exchange Market" (unpublished; New York: Salomon Center Working Paper No. S-98-3, New York University). 